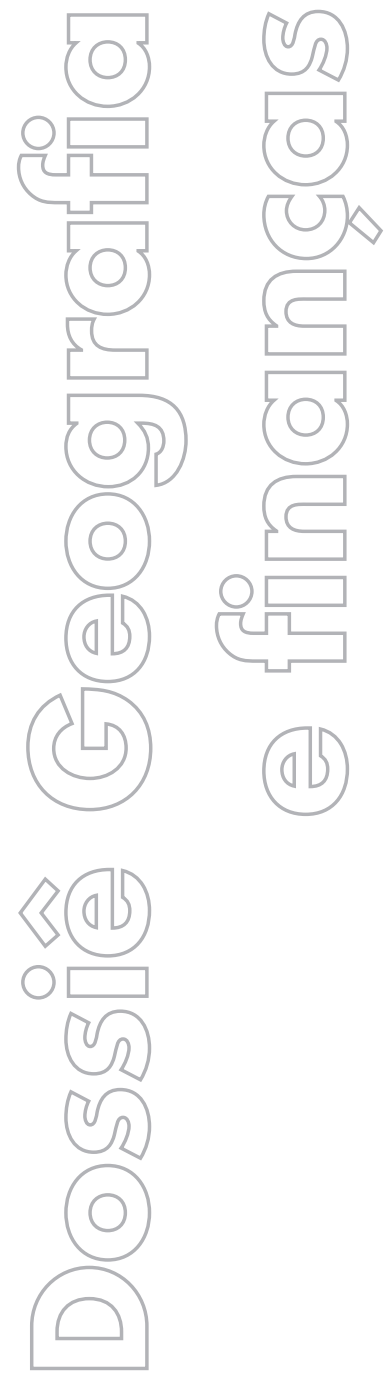

revista

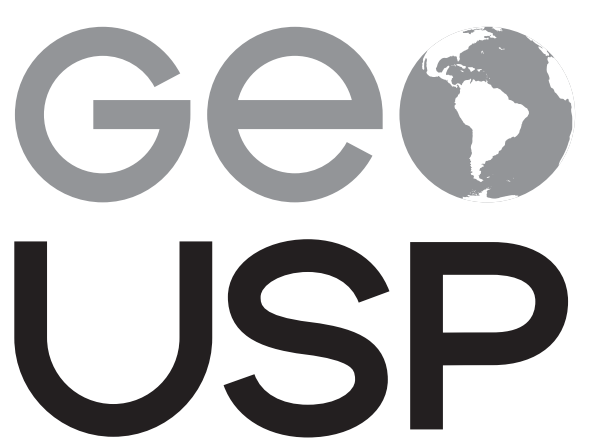

espaço e tempo

Volume $21 \cdot n^{\circ} 2$ (2017)

ISSN 2179-0892

\section{O fim do capitalismo dos} bancos de investimento? Uma geografia econômica do emprego e do poder financeiro

\author{
Dariusz Wójcik \\ Universidade de Oxford
}

p. $341-369$

Como citar este artigo:

WÓJCIK, D. O m do capitalismo dos bancos de investimento? Uma geografia econômica do emprego e do poder financeiro. Geousp - Espaço e Tempo (Online), v. 21, n. 2, p. 341-369, agosto. 2017. ISSN 2179-0892.

A GEOUSP agradece a Clark University, que autorizou a publicação deste artigo originalmente escrito em língua inglesa, com o título "The End of Investment Bank Capitalism? An Economic Geography of Financial Jobs and Power" em Economic Geography, 88(4):345-368. (C) 2012 Clark University.

Disponível em: < http://www.revistas.usp.br/geousp/ article/view/137838>. doi: http://dx.doi.org/10.11606/ issn.2179-0892.geousp.2017.137838.

\section{(c) $\underset{\mathrm{BY} \text { (i) }}{(\mathrm{SC}}$}

Este artigo está licenciado sob a Creative Commons Attribution 4.0 License. 


\title{
O fim do capitalismo dos bancos de investimento? Uma geografia econômica do emprego e do poder financeiro
}

\section{Resumo}

Este artigo investiga os padrões de emprego, remuneração e relações de poder no setor financeiro dos EUA entre 1978 e 2008 e demonstra que os bancos de investimento têm tido um papel central na indústria da securitização, que foi até aqui o segmento do setor financeiro estadunidense que se expandiu e contribuiu significativamente para a crescente desigualdade de renda. $\bigcirc$ poder dos bancos de investimento aumentou nos últimos 30 anos como consequência da crescente demanda por serviços de investimento, de mudanças tecnológicas, da desregulamentação e da globalização. Os bancos de investimento estão no centro do chamado shadow banking system, inventando muitos dos produtos usados por ele e muitas vezes dissimulando seu funcionamento e, assim, concorrendo decisivamente para a crise financeira global de 2007-2009. Com os principais bancos de investimento dos EUA convertidos em holdings e devido a uma possível re-regulação financeira, o futuro desses bancos é incerto. Seu relacionamento com fundos soberanos também implica incerteza, envolvendo tanto oportunidades quanto desafios. Este artigo identifica a geografia econômica dos bancos de investimento como uma das chaves para compreender a dinâmica da economia mundial contemporânea, numa abordagem de mesonível da geografia das finanças.

Palavras-chave: Bancos de investimento. Securitização. Crise financeira. Geografia econômica. Bancos de investimento.

\section{The End of Investment Bank Capitalism? An Economic Geography of Financial Jobs and Power}

\begin{abstract}
This article investigates employment patterns, remuneration, and power relations in the U.S. financial sector between 1978 and 2008. It demonstrates that investment banking has played a central part in the securities industry, which
\end{abstract}


has been by far the most expansive segment of the U.S. financial sector and a significant contributor to growing income inequality. The power of investment banking has risen over the past 30 years under the conditions of the growing demand for investment services, technological changes, deregulation, and globalization. Investment banks were at the heart of the shadow banking system, inventing many of the products used by it and often disguising its operation, thus contributing decisively to the outbreak of the global financial crisis of 2007-9. With leading U.S. investment banks converted into bank holding companies and the threat of reregulation, the future of investment banking is uncertain. One area of uncertainty is the banks' relationship with sovereign wealth funds, which involves both opportunities and challenges. The article identifies the economic geography of investment banking as one of the keys to understanding the dynamics of the contemporary world economy and promotes a mesolevel approach to geographies of finance.

Keywords: Investment banking. Securitization. Financial crisis. Economic geography. Investment banks.

Muitos achavam que o Goldman Sachs administrava a economia dos EUA. Agora temos certeza.

John Gapper, Financial Times, 24 set. 2008, p. 1

Os economistas, particularmente os financeiros, que diagnosticaram a crise financeira global (CFG) de 2007-2009 não conseguem entender exatamente qual o papel desempenhado pelas empresas e profissionais financeiros nesse processo. Ao contrário da mídia, que antecipadamente critica bancos e banqueiros, os economistas normalmente buscam entender as causas da crise com base em fatores mais abstratos e estruturais, como o fracasso dos mercados financeiros irrestritos (Stiglitz, 2010), o comportamento irracional dos investidores (Shiller, 2008), ou os desequilibrios comerciais e financeiros em nível global (Rajan, 2010). A atenção dada a bancos e banqueiros parece incompatível com o conhecimento e os estudos em economia, segundo os quais testemunhamos nas últimas três décadas um processo de desintermediação, em que o papel central dos bancos na coleta de depósitos financeiros e na concessão de empréstimos foi substituído por investidores e mutuários que têm acesso direto aos mercados de capitais (Mishkin, 2006). De acordo com os estudos sobre desintermediação, a narrativa econômica emergente da CFG na área da economia concentra-se na interconectada e complexa natureza das finanças, segundo a qual as instituições e mercados financeiros tornaram-se mais interconectados e os instrumentos financeiros mais complexos, aumentando a gravidade dos eventos ou riscos "de cauda" (tail risks: eventos de baixa probabilidade, mas com consequências potencialmente desastrosas), também denominados "cisnes negros" (Taleb, 2008). Governos, reguladores e cientistas não conseguiram acompanhar esses desenvolvimentos na área, daí a crise. A retórica da desintermediação e da 
complexidade - sua irmã mais nova -, faz com que o sistema financeiro pareça composto por forças de mercado abstratas e atores anônimos, cuja identidade consequentemente vira uma questão insignificante (Christophers, 2009).

No entanto, vários estudiosos se opõem à visão do setor financeiro como um mero intermediário, que, devido ao suposto processo de desintermediação, estaria se desvanecendo no conjunto da economia. Por muito tempo, economistas políticos e outros cientistas sociais, particularmente no lado radical da área, colocaram o setor financeiro no centro das relações de poder que moldam a economia estadunidense e internacional, com a proliferação de termos como "Complexo Wall Street-Tesouro-FMI" (Bhagwati, 1998) ou "novo sistema de Wall Street" (Gowan, 2009), não tocando no debate mais amplo sobre o neoliberalismo (Harvey, 2011). Para os demais pesquisadores, o crescente campo interdisciplinar de estudos da financeirização documentou e alertou sobre o papel excessivo e prejudicial do setor financeiro na vida econômica e social (Epstein, 2005; Froud et al., 2006; Engelen et al., 2011; Savage; Williams, 2008). A CFG pode ao menos ter servido como uma possível validação dos estudos críticos de economia política e de financeirização; porém, o problema compartilhado por ambas as abordagens é a espacialização insuficiente do setor financeiro, dando pouca atenção ao espaço e à localidade, tanto em relação a processos quanto a efeitos (French; Leyshon; Wainwright, 2011). Como a financeirização se difunde pelo espaço? Qual o papel que determinados locais desempenham nesse processo? Qual é o impacto da financeirização em certos lugares? Essas e muitas outras questões ainda aguardam respostas empiricamente satisfatórias.

objetivo deste artigo é contribuir para os estudos que espacializam o entendimento da financeirização, lançando o foco no emprego, na remuneração e no poder do setor financeiro dos EUA. Este artigo desconstrói a evolução desse setor estadunidense por meio da técnica forense de "descascar cebola" (um ato gradual de aquisição de evidências), com apresentação do quadro teórico após esta introdução. A parte empírica deste texto começa analisando o emprego no setor financeiro entre 1978 e 2008 nos EUA, como um todo, e em seu centro financeiro - Manhattan. Essa análise ajuda a definir a indústria da securitização como um subsetor fundamental para o crescimento fenomenal do setor financeiro em termos de emprego e salários nas últimas três décadas e como um dos principais contribuintes para a crescente desigualdade de renda entre empregos financeiros e não financeiros, entre Manhattan e o resto dos EUA e dentro de Manhattan. Em seguida, este artigo analisa a estrutura da indústria da securitização, com a identificação dos bancos de investimento como sua elite, além de fazer um esboço dos principais fatores que contribuíram para o aumento exponencial e transformação desse mercado. A seção seguinte então considera o crescimento da indústria da securitização nas principais economias para além dos EUA, destacando a disseminação internacional do capitalismo dos bancos de investimento, acompanhada por um apanhado geral sobre o papel dos bancos de investimento na CFG e questionando se estamos testemunhando um impacto significativo da erosão do poder desses bancos. A seção final apresenta um resumo dos resultados e orientações para pesquisas futuras.

A principal implicação deste artigo para a geografia econômica é que o estudo dos bancos de investimento como uma indústria é uma das chaves para compreendermos tanto as três últimas décadas da história do capitalismo quanto seu futuro e as causas e consequências 
da CFG. Apesar de serem de grande interesse para os geógrafos econômicos, a maioria dos estudos sobre bancos de investimento concentra-se em produtos ou práticas específicas desse setor (ex. Hall, S., 2007); em bancos de investimento como agentes do neoliberalismo (ex. Leyshon; Thrift, 1997); na mobilidade dos banqueiros de investimento (Beaverstock, 2007); ou em bancos de investimento como exemplos de vários aspectos da globalização (ex. Jones, 2002). Desse modo, mais estudos são necessários para entender a estrutura da indústria e sua posição e poder na economia e na sociedade dentro e entre países e centros financeiros. Os bancos de investimento podem ser investigados como sendo a elite do setor financeiro, mas também podem ser entendidos como o setor inteiro de produção de serviços. Nenhum outro grupo profissional no setor de produtivos de serviços é tão altamente recompensado, com incomparáveis níveis de acesso e interação com executivos corporativos. Considerando que a comunidade de geógrafos pesquisadores de finanças é relativamente pequena, o foco nos bancos de investimento pode contribuir muito com a ciência social das finanças.

Este artigo tem uma implicação normativa, além de comprovar a visão do poder como algo construído e reconstruído e não como uma entidade estrutural e independente da vontade de qualquer pessoa, visão confirmada pela posição do setor financeiro no centro dos circuitos de capital (Allen, 2009). $\bigcirc$ presente texto comprova que os banqueiros de investimento se tornaram a elite financeira nas últimas décadas, usando seu papel no sistema financeiro global para desviar recompensas e prêmios em seu favor. Essa leitura do setor financeiro abre espaço para o engajamento político, tornando plausível questionar o fim do capitalismo dos bancos de investimento - bem como o futuro para além dessa indústria.

\section{Uma geografia econômica do poder e do emprego financeiro}

O emprego e o poder são pontos centrais da pesquisa em geografia econômica. A ênfase no emprego fundamenta-se na tradição keynesiana, que o considera principal variável econômica. $\bigcirc$ emprego lucrativo é a principal maneira pela qual as pessoas e as sociedades se sustentam e a criação de novos postos produz efeitos multiplicadores para o resto da economia (Skidelsky, 2010). $\bigcirc$ interesse pelo poder tem suas raízes na tradição marxista, segundo a qual a atividade econômica é sustentada pelas relações sociais, que, por natureza, envolvem níveis desiguais de poder (Singer, 2000). A geografia econômica quantitativa positivista, que se concentra na localização da atividade econômica, requer o mapeamento do emprego e dos fatores que afetam sua distribuição (Dicken; Lloyd, 1990). A geografia econômica marxista, por sua vez, busca compreender como as relações de poder desiguais estão inscritas no espaço (Harvey, 1973).

Doreen Massey (1995) apresenta uma importante síntese do tratamento do emprego e do poder, promovendo uma perspectiva da geografia econômica que associa a análise das distribuições espaciais das atividades econômicas com a compreensão dessas distribuições como causas e consequências das relações sociais, inerentemente imbuídas de poder. Essa dupla estratégia analítica é necessária. Por um lado, analisar as distribuições espaciais em si mesmas pode levar ao reducionismo espacial e ao fetichismo. Por outro lado, uma análise das relações de poder sem considerar a distribuição espacial acaba tirando o foco geográfico dessa área de pesquisa, tornando-a pouco distinguível da sociologia ou da ciência política. Como disse Massey (1995, p. 120), "a geografia não é apenas um produto das relações sociais; é parte integrante de seu desenvolvimento". 
O convite de Massey (1995) para o desenvolvimento de uma exploração integrada dos caminhos quantitativos e qualitativos do emprego e do poder certamente não teve o retorno esperado. Geógrafos e economistas mais econométricos voltaram-se para a economia geográfica, que analisa os padrões de emprego na busca de explicações para a aglomeração espacial e a especialização, tendo pouco a dizer sobre o poder (Brakman; Garretsen; Marrewijk, 2009). A proximidade espacial nessa abordagem tende a ser fetichizada, com pouca apreciação pelo fato de que a separação espacial das atividades econômicas pode desempenhar uma função importante na tomada de decisões econômicas, auxiliando executivos nos processos de reestruturação e downsizing corporativos em localidades distantes de suas casas (Landier; Nair; Wulf, 2009). Por outro lado, o poder permanece central para a perspectiva da economia cultural na geografia econômica, que gerou teorias sofisticadas sobre a espacialidade do poder, mas não nutriu interesse no mapeamento sistemático dos padrões de emprego (Amin; Thrift, 2004).

Neste artigo, busco uma reaproximação com a ideia de Massey (1995) para associar a análise dos padrões de emprego e de poder, focando-as no setor financeiro, que é provavelmente a área mais controversa da economia no início do século XXI. O poder é aqui entendido mais amplamente como a influência econômica, política e cultural do setor financeiro, baseado na tênue possibilidade de consentimento, persuasão e liderança intelectual, e não na corrupção ou coerção (Arrighi, 2010). $\bigcirc$ poder e a sua espacialidade podem ser obtidos pela análise das tendências de emprego e remuneração, bem como por meio de uma análise funcional das relações dentro e fora do setor financeiro. Essa investigação se enriquece com a análise do impacto da regulamentação e da tecnologia, ajudando, assim, a identificar e localizar as áreas do setor financeiro e os lugares onde o poder se concentra e a partir do qual ele emana.

Este artigo apresenta uma abordagem de mesonível para o emprego e o poder no setor financeiro, colocando-se entre a abordagem micronível da antropologia, focada na vida cotidiana desse setor (Randy Martin, 2002; Langley, 2008), e a abordagem macroeconômica da economia política, que considera a financeirização uma etapa do capitalismo financeiro (Arrighi, 2010). $\bigcirc$ uso de uma abordagem de mesonível não é novidade. Afinal, as principais estratégias da já estabelecida literatura sobre geografias financeiras ancoram-se na divisão de espaços (ou sistemas) financeiros nacionais em subsetores, grupos de empresas e centros de atividade financeira, analisando-os por meio de comparações intra e internacionais (Clark; Wójcik, 2007; Ron Martin, 1999; Leyshon; Thrift, 1997). O que é original, no entanto, é a combinação da análise do emprego, da remuneração e do poder em um contexto histórico e espacial, bem como a aplicação dessa análise aos bancos de investimento.

A abordagem de mesonível para a geografia financeira baseada em Massey (1995) tem três vantagens principais. Primeiro, combinando a análise de padrões espaciais e relações de poder, ela considera tanto a estrutura como a agência (agency), sem privilegiar uma ou outra. Em segundo lugar, ao se concentrar no emprego e na remuneração, essa abordagem posiciona o setor financeiro na economia real, em vez de cultivar uma visão desconectada dela [da economia real], que inevitavelmente pode levar à negligência do espaço e do lugar. Por extensão, o estudo do emprego e da remuneração é uma maneira um tanto rudimentar, mas importante, de investigar o impacto do setor financeiro nos níveis de desigualdade de desenvolvimento. Finalmente, essa é uma abordagem que considera não apenas a dimensão espacial e a econômica, mas também os aspectos político, social e cultural, satisfazendo assim o convite a uma abordagem integradora do setor financiamento (Pike; Pollard, 2010). 
Este artigo aproxima-se da geografia das finanças e dos estudos da financeirização e inspira-se particularmente na pesquisa de Leyshon e Thrift (1997) sobre a reestruturação do setor financeiro britânico nos anos 1980 e no trabalho de Krippner (2005) sobre o emprego e a lucratividade das empresas financeiras dos EUA. Minha ambição, no entanto, vai além de uma contribuição que promova a geografia econômica ou a espacialização da pesquisa em financeirização, pois busco demonstrar que mesmo uma análise exploratória relativamente básica do setor financeiro como uma indústria, com foco no emprego e nas relações de poder, pode contribuir para o diagnóstico da crise financeira global de 2007-2009. Especificamente, essa análise pode nos ajudar a identificar a indústria da securitização, em particular os bancos de investimentos, como um hotspot de poder fundamental na geração da crise e cuja potencial reestruturação após a crise pode criar as fundações para uma grande transformação da economia mundial no século XXI.

\section{A ascensão da indústria da securitização}

Para situar os bancos de investimento no setor financeiro e na economia dos EUA, investiguei a transformação do setor financeiro estadunidense em termos de emprego e folha de pagamento entre 1978, véspera da desregulamentação financeira da era Reagan, e 2008, pico da CFG. O setor financeiro é definido de forma ampla, composto por quatro categorias de três dígitos do Sistema Norte-Americano de Classificação das Indústrias (Naics) e pelas categorias correspondentes da Classificação Industrial Padrão: intermediação de crédito e atividades relacionadas (doravante "setor de crédito"); securitizações, contratos de commodities e outros investimentos financeiros e atividades relacionadas ( "a indústria da securitização"); transportadoras de seguros e atividades relacionadas ("seguros"); e setor imobiliário. $\bigcirc$ setor de crédito é constituído por instituições que lidam com empréstimos (empresas que recebem depósitos ou que se concentram exclusivamente na geração de empréstimos, como credores de hipotecas ou empresas de cartões de crédito). A indústria da securitização trata da produção, distribuição e troca de títulos securitizados, incluindo obrigações, ações, títulos garantidos por ativos e derivativos. Os dados foram obtidos do banco de dados dos Padrões Municipais de Comércio (County Business Patterns) do Censo dos EUA, coletados com base em cada estabelecimento comercial. Por exemplo, para o JPMorgan, uma holding bancária que abrange atividades de crédito e títulos securitizados, dados sobre emprego e folha de pagamento em cada escritório foram atribuídos a cada localidade e classificados de acordo com a atividade principal do escritório. Os dados de emprego são de meados de março de um determinado ano e os de folha de pagamento referem-se aos pagamentos totais do ano (incluindo bônus). Não há dados disponíveis sobre a distribuição de empregos entre os escritórios centrais e de apoio ou entre os níveis gerencial e administrativo. Os dados também não incluem autônomos, particulares, funcionários ferroviários e agrícolas, nem a maioria dos funcionários em postos governamentais. Na análise, os dados foram usados para todos os anos entre 1978 e 2008. Com o intuito de manter essa análise breve, a discussão a seguir concentra-se em comparações entre 1978 e 2008.

A sequência de etapas analíticas revelou uma grande mudança na posição e estrutura do setor financeiro dos EUA. A participação das finanças no emprego total (Figura 1) manteve-se notavelmente estável em 6,6\% em 1998 e 2008, variando muito pouco, de 6,4\% para 7,1\%, nesse período. No entanto, dentro do setor financeiro, a indústria da securitização cresceu signi-

ficativamente à custa do setor de créditos e seguros, com seus empregos absolutos que pularam 
de 177 mil postos para 974 mil, resultando em participação de $0,3 \%$ para 0,8\% no cenário de emprego nos EUA. Diferente dessa participação estável nos empregos, a folha de pagamento total do setor financeiro aumentou gradualmente de 6,7\% em 1978 para 11,3\% em 2008 (Figura 2). Como principal contribuinte para esse aumento, temos a indústria da securitização, que evoluiu de menor para maior pagador na área financeira, aumentando sua participação de 0,5\% para $3,6 \%$. Nas últimas três décadas, a folha de pagamento por pessoa (salários) no setor financeiro distanciou-se profundamente do resto da economia dos EUA (Figura 3). Em 1978, um profissional médio da área financeira ganhava apenas $2 \%$ a mais do que um trabalhador médio de outra área; 30 anos depois, ele passa a ganhar mais de $81 \%$, em comparação. Assim, nas últimas três décadas, um trabalhador de finanças ganhou, em média, uma vantagem de $2 \%$ por ano em remuneração, comparado a um trabalhador de área não financeira. Dito de outra forma, enquanto o poder de compra do salário médio estadunidense fora do setor financeiro não aumentou, nesse setor, o poder de compra cresceu 77\% (Figura 4). Dentro do setor financeiro, a indústria da securitização foi líder absoluta em aumentos salariais. Em 1978, um trabalhador médio desse setor ganhava o dobro do que um trabalhador de área não financeira; ao passo que em 2008, ele chega a ganhar quase cinco vezes mais. Na verdade, em 2008, não havia uma única categoria Naics, por menor e mais seleta que fosse, que chegasse perto da folha de pagamento média de US\$ 189.000,00 (anuais) da indústria da securitização (Figura 5).

\section{Figura 1 - Participação dos setores financeiro, de seguros e imobiliário (Fisi) nos níveis de emprego nos EUA}

2008

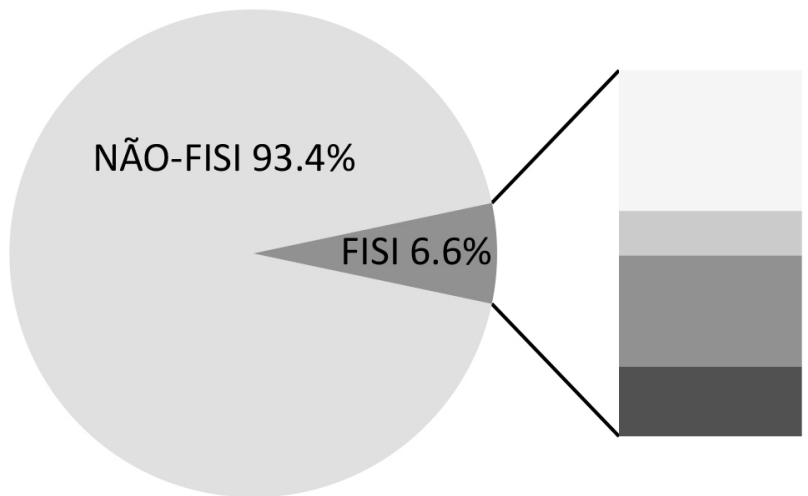

Crédito $2.5 \%$

Títulos securitizados $0.8 \%$

Seguros $2.0 \%$

Setor imobiliário 1.3\%

1978

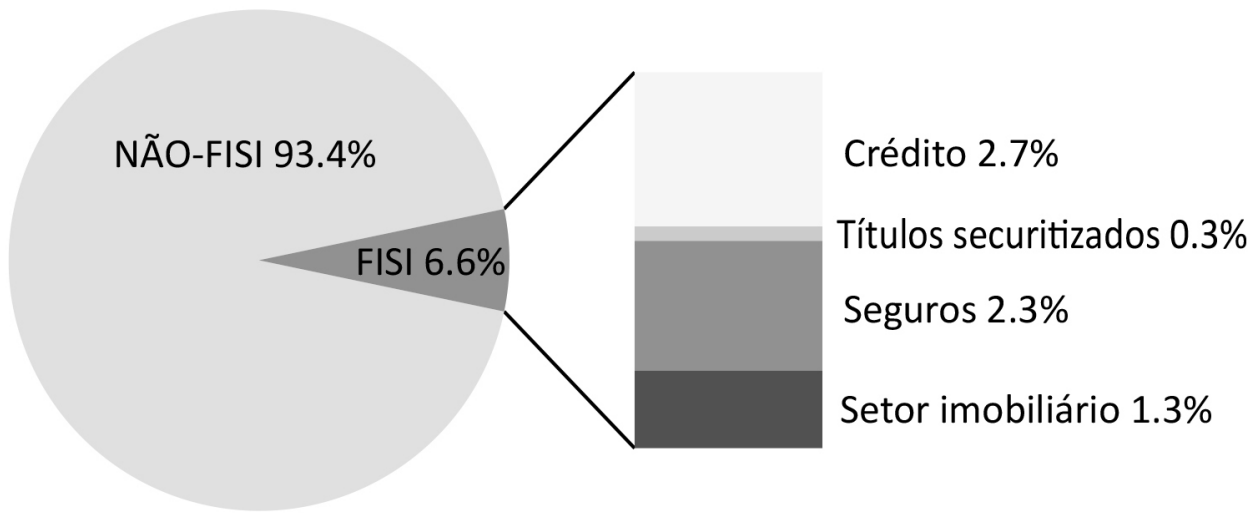

fonte: $\bigcirc$ autor, com base em dados dos Padrões Comerciais Municipais. 
Figura 2 - Participação dos setores financeiro, de seguros e imobiliário (Fisi) na remuneração nos EUA

2008

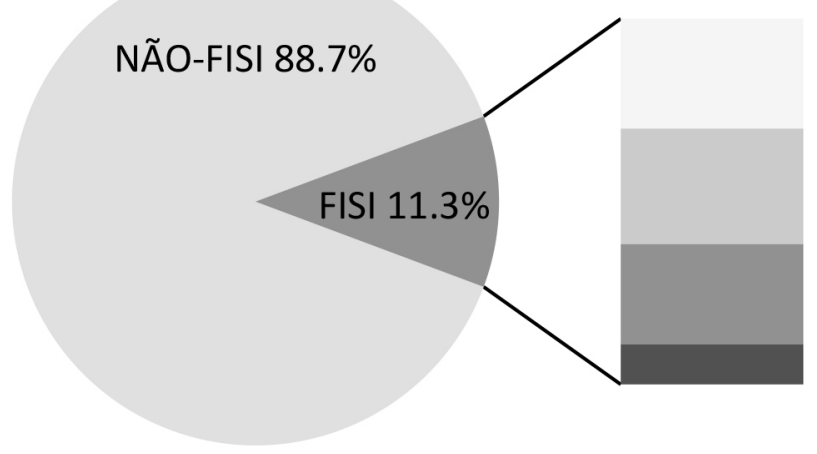

Crédito $3.4 \%$

Títulos securitizados $3.6 \%$

Seguros $3.1 \%$

Setor imobiliário $1.2 \%$

1978

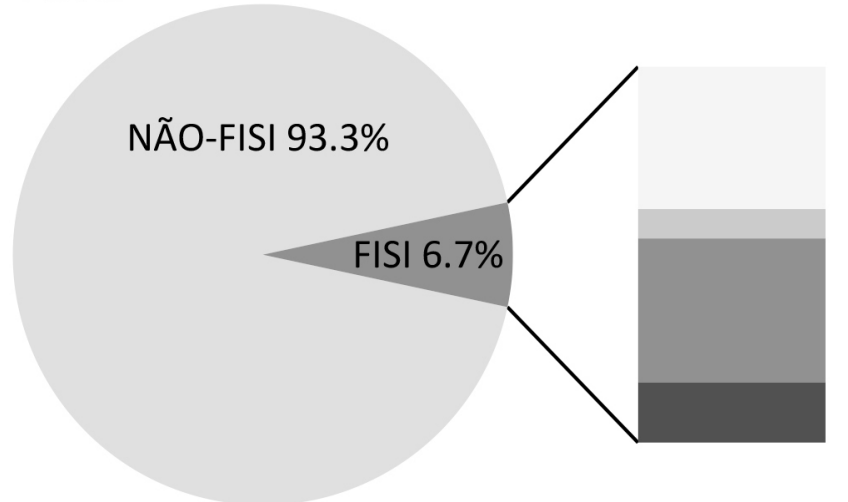

Crédito $2.5 \%$

Títulos securitizados $0.5 \%$

Seguros $2.6 \%$

Setor imobiliário $1.1 \%$

fonte: $\bigcirc$ autor, com base em dados dos Padrões Comerciais Municipais.

Figura 3 - Remuneração média por pessoal no setor financeiro em relação a empregos em setores não financeiros

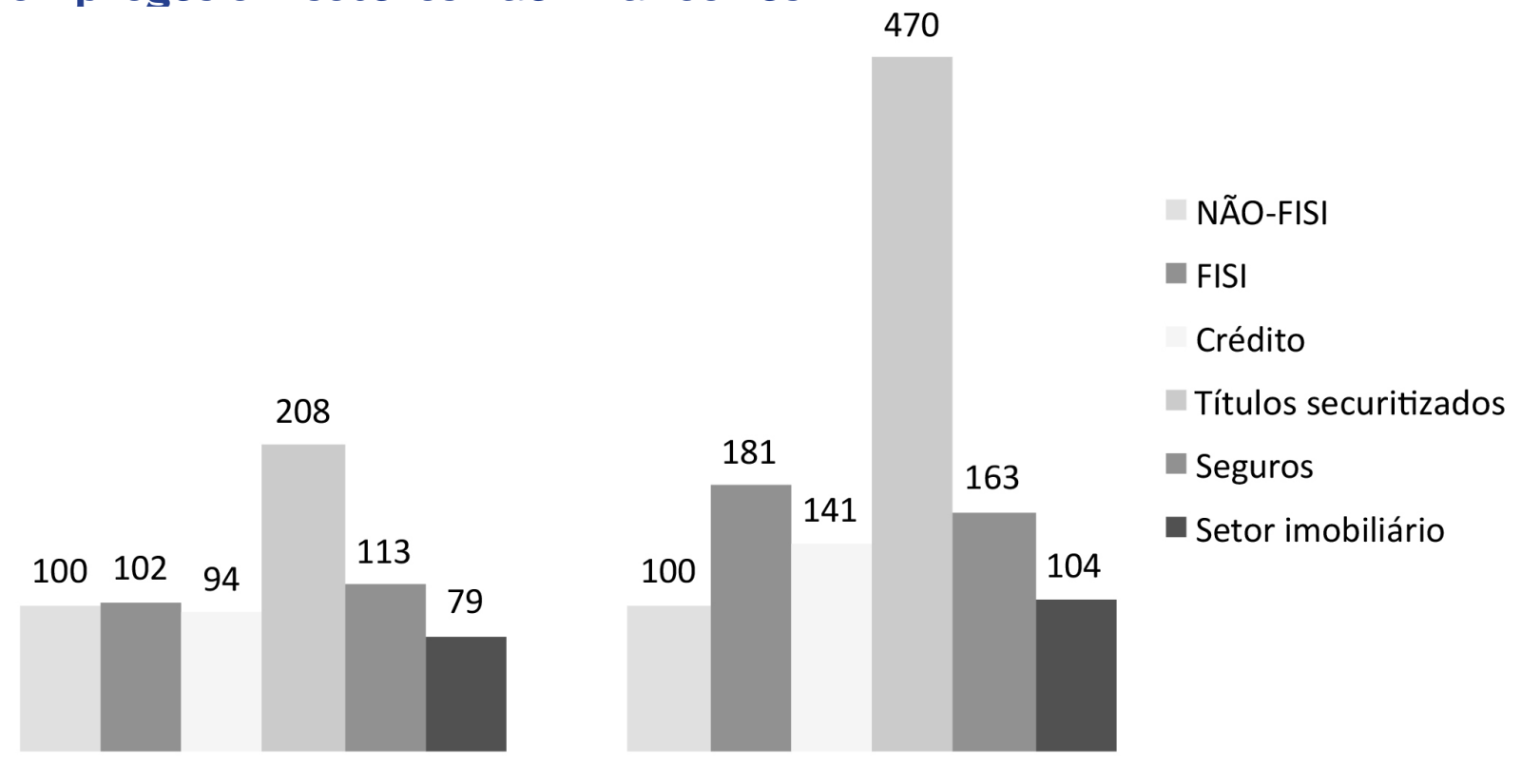

1978

2008

fonte: $\bigcirc$ autor, com base em dados dos Padrões Comerciais Municipais. 
Figura 4 - Percentual de variação na média real de remuneração anual por pessoa entre 1978-2008

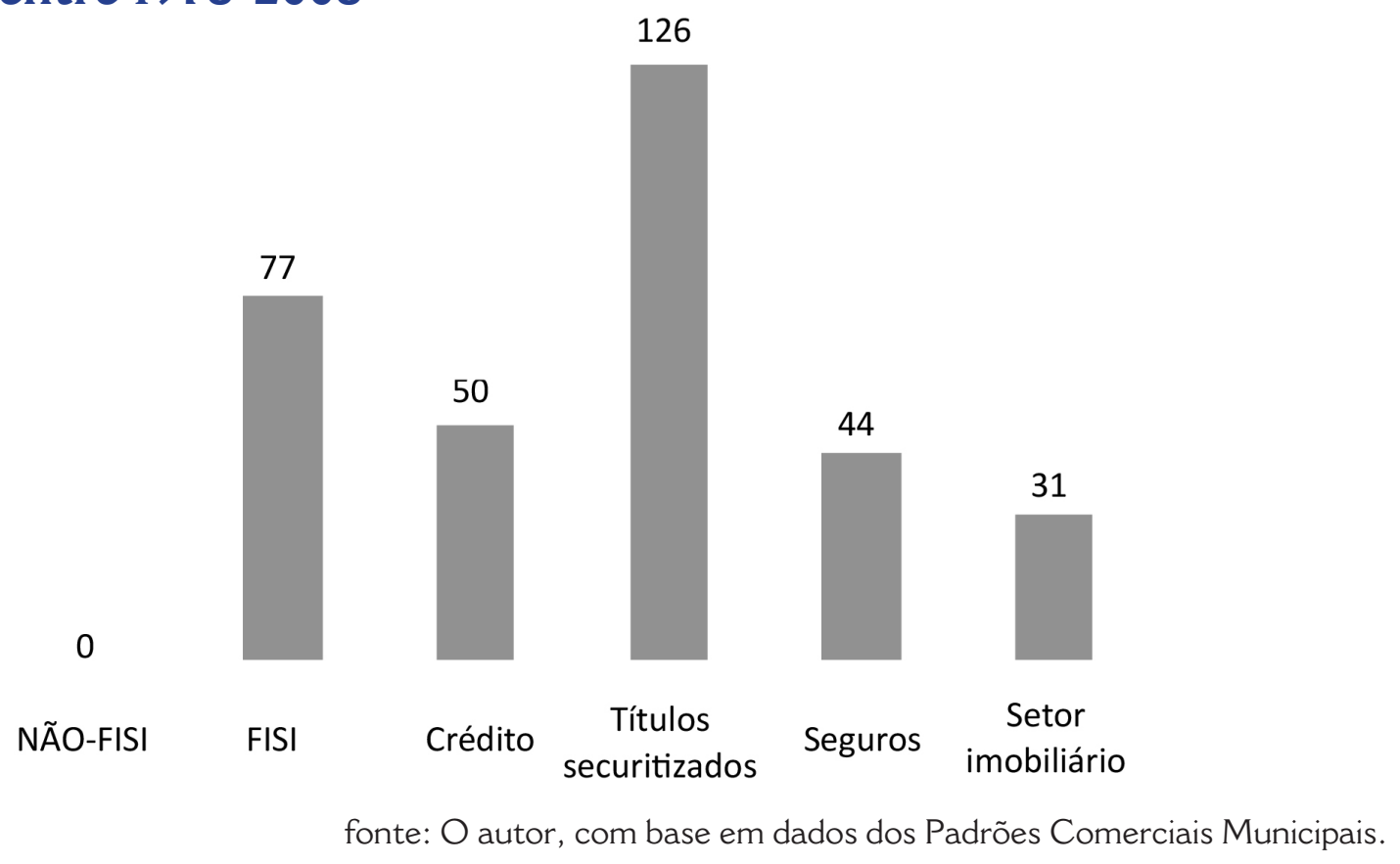

Figura 5 - Remuneração média anual de 2008 por pessoa, em indústrias e setores indicados (em dólares americanos)

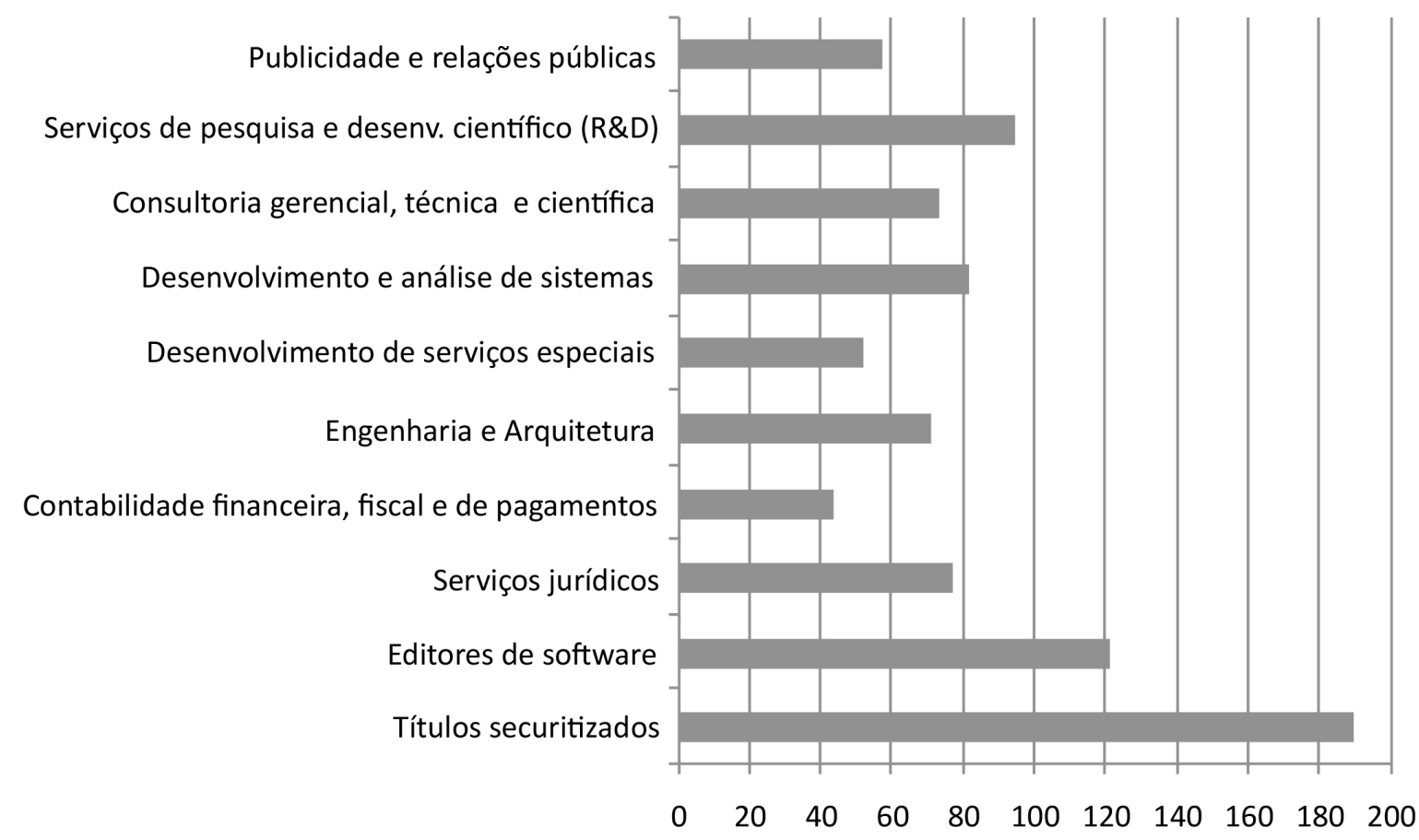

fonte: $\bigcirc$ autor, com base em dados dos Padrões Comerciais Municipais.

Se dermos um zoom em Manhattan (Municipalidade de Nova York), a "casa" de Wall Street, veremos mais dimensões dessa transformação das finanças. Embora os empregos do setor financeiro em Manhattan tenham caído de 19,6\% para 18,6\% (atingindo um pico de 22,8\% em 1988), a indústria da securitização evoluiu de menor para maior empregador nesse setor (Figura 6). Em 
2008, essa indústria empregou 198 mil pessoas - mais do que o total dos setores de crédito, seguros e imobiliário juntos. A mudança na folha de pagamentos foi drástica. A participação do setor financeiro na folha de pagamentos de Manhattan cresceu gradualmente de 21,4\% para 46,2\%, com aumento de 5,9\% para 34,3\% apenas na indústria da securitização (Figura 7). Representando menos de 10\% da força de trabalho de Manhattan, a indústria da securitização compõe mais de um terço do total da folha de pagamento estadunidense e quase três quartos da follha de pagamento em finanças. Em 1978, mesmo em Manhattan, um posto de trabalho no setor financeiro não era algo especial. O salário médio nesse setor era apenas 13\% mais alto do que em áreas não financeiras (Figura 8). Já em 2008, o salário mostrou-se 273\% maior, devido principalmente à expansão da indústria da securitização, incluindo os salários desse subsetor. É interessante notar que, embora a participação de Manhattan em postos de trabalho na indústria da securitização estadunidense tenha se reduzido gradualmente de $36 \%$ para $20 \%$, sua participação na follha de pagamento permaneceu estável em aproximadamente $40 \%$ ao longo do tempo (Figura 9). Essa maior participação em folha de pagamento do que em emprego reflete o fato de que Manhattan atua como o centro da indústria da securitização abrigando os empregos mais bem pagos do país, comandando a expansão da indústria no resto dos EUA e internacionalmente. Realmente, em 1978, o salário médio na indústria da securitização em Manhattan era apenas 13\% maior do que no resto dos EUA, tornando-se 160\% maior em 2008 - evidência da maior centralização que ocorre na própria indústria.

Figura 6 - Participação dos setores financeiro, de seguros e imobiliário (Fisi) nos níveis de emprego em Manhattan

2008

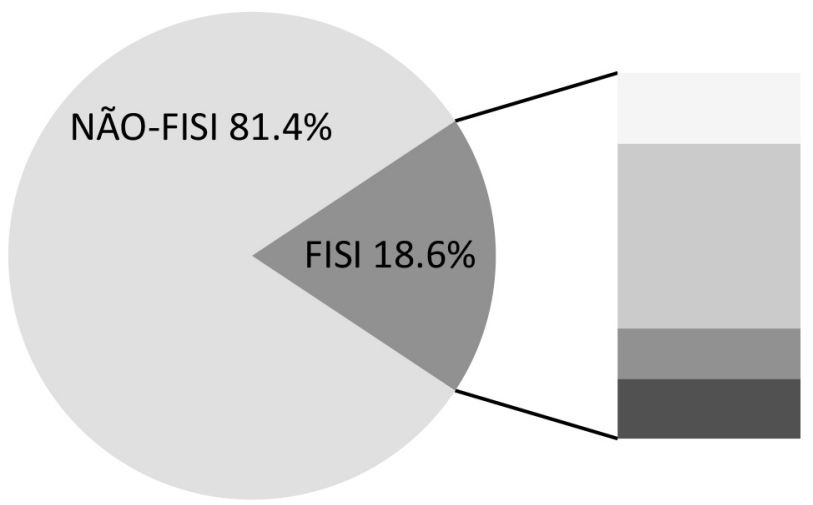

Crédito $3.6 \%$

Títulos securitizados $9.4 \%$

Seguros $2.6 \%$

Setor imobiliário 3.0\%

1978

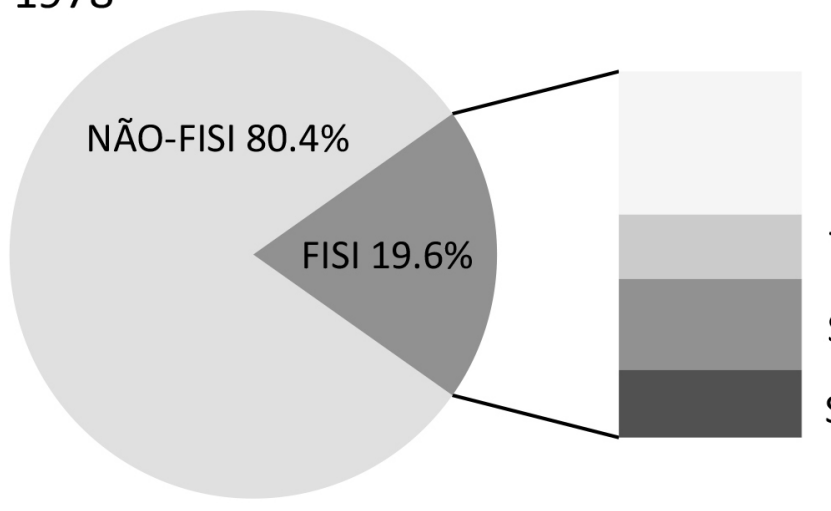

Crédito $7.7 \%$

Títulos securitizados $3.4 \%$

Seguros $4.9 \%$

Setor imobiliário 3.6\%

fonte: $\bigcirc$ autor, com base em dados dos Padrões Comerciais Municipais. 
Figura 7 - Participação dos setores financeiro, de seguros e imobiliário (Fisi) na remuneração em Manhattan
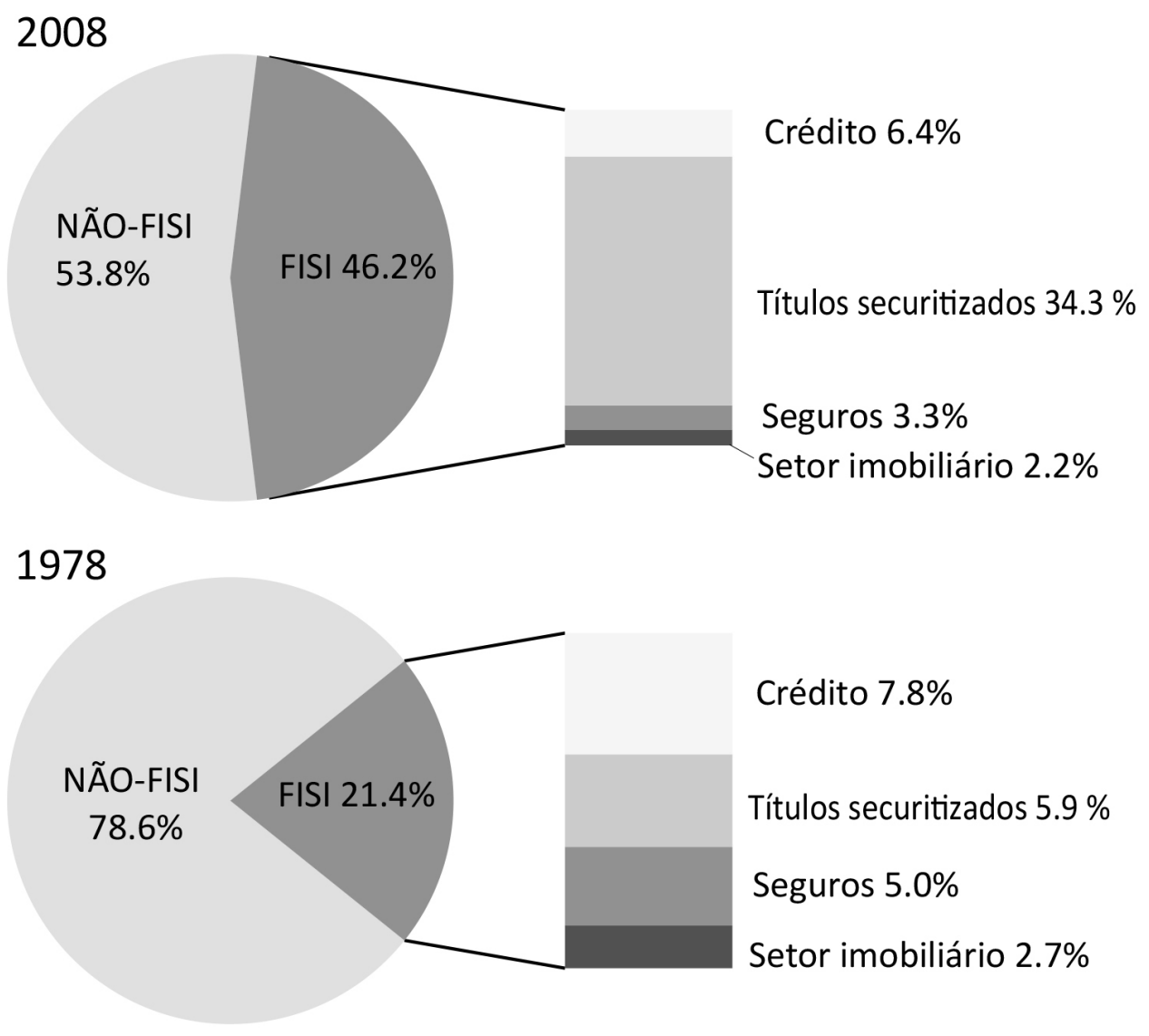

fonte: $\bigcirc$ autor, com base em dados dos Padrões Comerciais Municipais.

Figura 8 - Remuneração média por pessoal no setor financeiro em relação a empregos em setores não financeiros em Manhattan

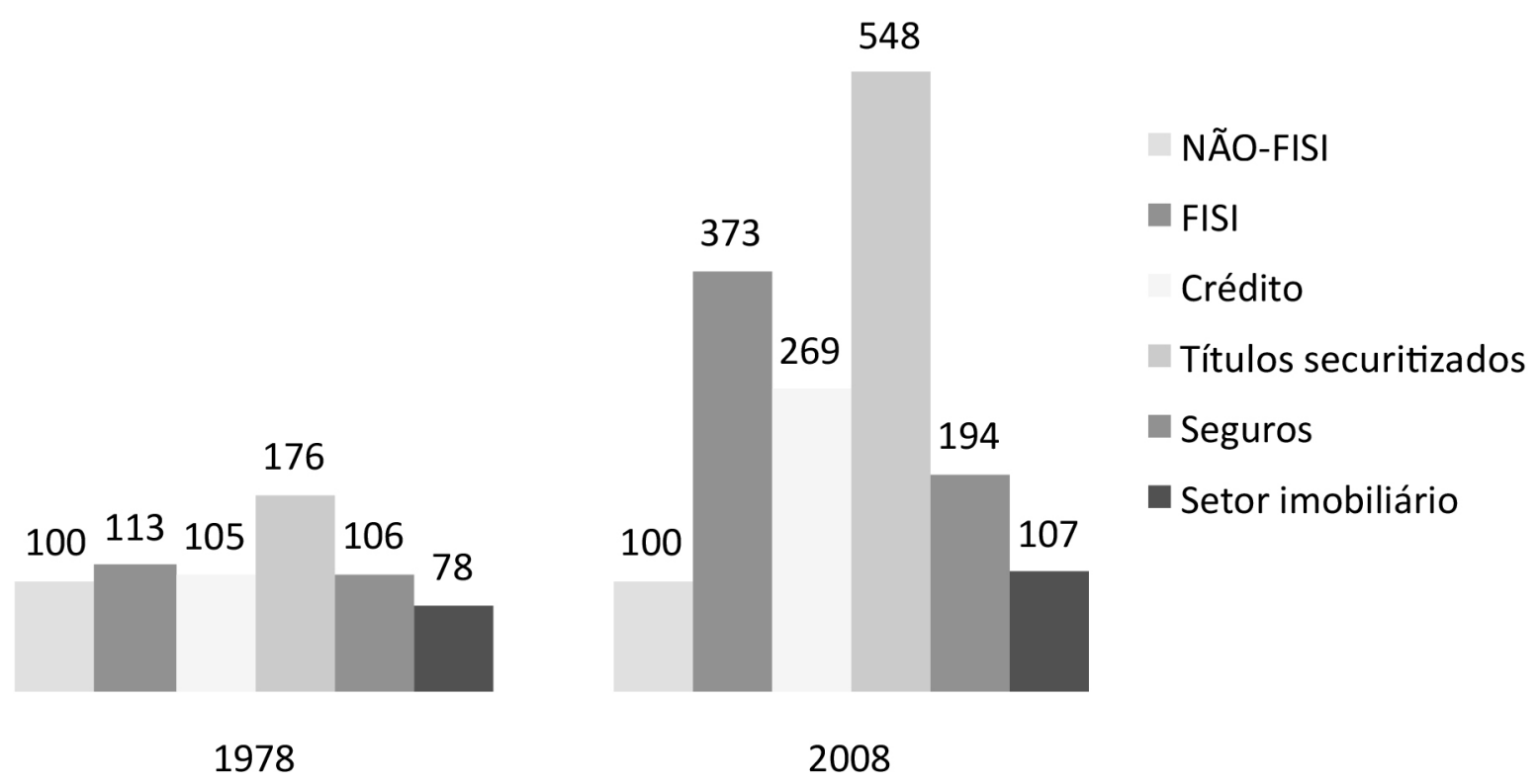




\section{Figura 9 - Participação de Manhattan no nível total de emprego e remu- neração na indústria da securitização}
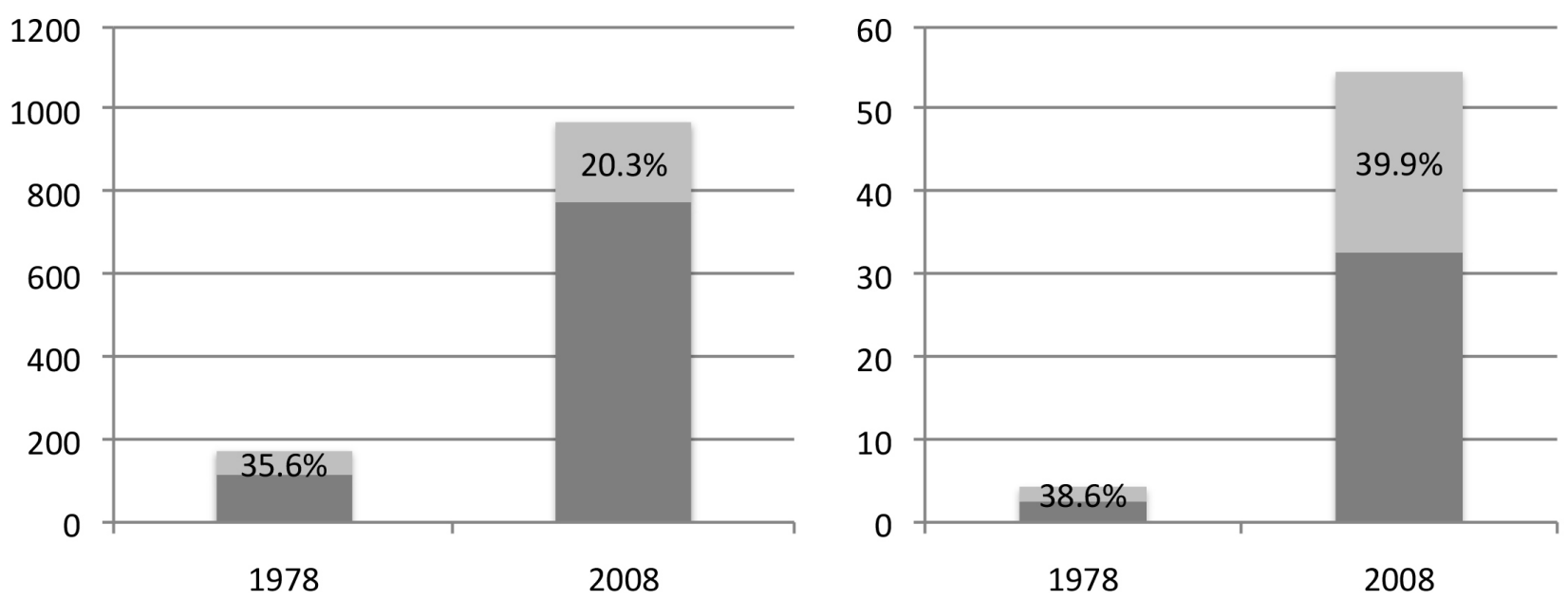

\section{Manhattan \\ Resto dos EUA、}

fonte: $\mathrm{O}$ autor, com base em dados dos Padrões Comerciais Municipais.

Para resumir, o principal processo que esses padrões de emprego e de remuneração revelam é a ascensão fenomenal da indústria da securitização. No decorrer das três décadas analisadas, papeis securitizados convencionais, como ações ordinárias (equities) e títulos, cresceram significativamente, os mercados de derivativos se desenvolveram e expandiram, e a securitização se estendeu também para empréstimos (incluindo hipotecas), que até então era considerado um negócio exclusivo do setor de crédito. Embora exista uma vasta literatura sobre esses processos, que não precisa ser repetida aqui (ex. Wójcik, 201la; Leyshon; Thrift, 2007), esta seção mostra que esses processos tiveram impacto real na geografia básica do emprego nos EUA. Seria inclusive mais preciso dizer que a economia estadunidense foi securitizada, ao invés de financeirizada. A CFG está intimamente relacionada ao boom dos preços imobiliários, mas o aumento do emprego e dos salários no setor imobiliário foi modesto em comparação com o resto da área financeira, e insignificante em relação à indústria da securitização. A análise aqui feita também indica que Manhattan foi de centro geral de serviços financeiros para centro especializado da indústria da securitização, cuja expansão contribuiu significativamente para a crescente desigualdade de renda entre empregos financeiros e de outras áreas, tanto entre Manhattan e no resto dos EUA quanto dentro de Manhattan. Essa indústria estabeleceu-se no topo da hierarquia industrial estadunidense em termos de remuneração por pessoa, superior a qualquer outro serviço profissional na área de negócios, de economia do conhecimento ou na indústria criativa.

A ascensão da indústria da securitização não foi necessariamente uma causa direta ou principal da desigualdade de renda nos EUA. Estudos futuros sobre essa questão, no entanto, devem considerar esse avanço como importante fator no cenário de desigualdade de renda (Warf, 2004). Rhaguram Rajan (2010), ex-economista-chefe do FMI, acertadamente apontou 
esse desnível como um grande defeito da economia estadunidense e como um dos fatores estruturais por trás da CFG. No entanto, ele não fez uma conexão entre a desigualdade de renda e os excessos no setor financeiro. Essa desconexão evidencia a vantagem de se adotar uma abordagem de mesonível. Ao analisar os padrões de emprego e remuneração em diferentes subsetores da área financeira ao longo do tempo e no espaço, a geografia econômica pode contribuir para o estudo das causas e consequências da CFG.

\section{Por dentro da indústria da securitização}

Após identificar a indústria da securitização como motor da financeirização da economia estadunidense, agora passo à análise de sua estrutura. É um tanto quanto comum chamar qualquer intermediação nos mercados securitizados de operações bancárias de investimento (investment banking), mas essa é uma simplificação grosseira (Morrison; Wilhelm, 2007). Primeiro, é preciso distinguir entre o lado da venda e o lado da compra desse mercado (ver Figura 10). $\bigcirc$ lado da venda funciona principalmente com os emissores de títulos securitizados, incluindo empresas emissoras de ações e títulos; governos federais, estaduais e municipais emissores de títulos, além de bancos que geram empréstimos a serem securitizados. $\bigcirc$ lado da compra funciona principalmente com investidores individuais e institucionais. Entre eles estão os facilitadores das trocas, principalmente sob a forma de bolsas (de valores e de mercadorias) e câmaras de compensação (Harris, 2003). Em 2008, o lado da venda, o lado da compra e os facilitadores das trocas tinham 534 mil, 432 mil e oito mil funcionários, respectivamente.

\section{Figura 10 - Estrutura básica da indústria da securitização}

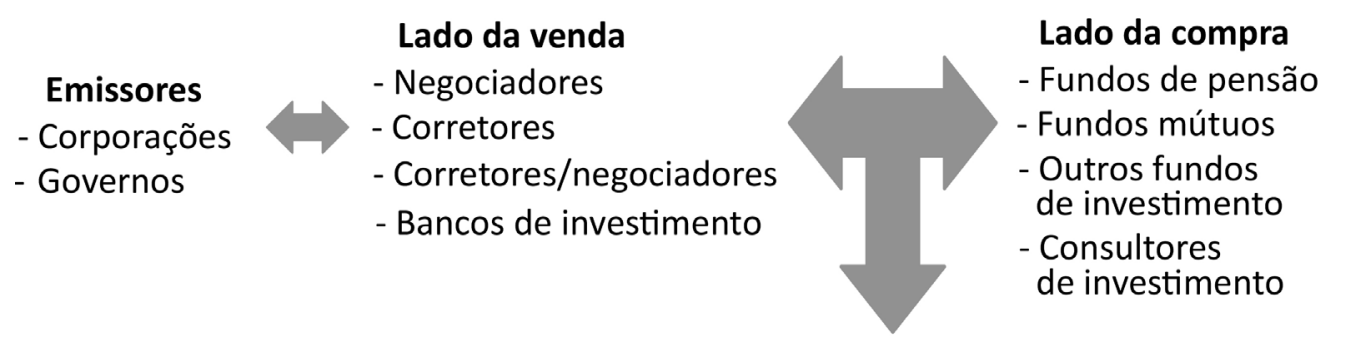

Lado da compra

- Fundos de pensão

- Fundos mútuos

- Outros fundos

de investimento

de investimento
Investidores

Facilitadores de trocas

- Bolsas

- Câmaras de Compensação

fonte: $\mathrm{O}$ autor.

Definidas de forma restrita, os bancos de investimento restringem-se ao lado da venda, focados em aprovar emissões de novos produtos securitizados; em negociar títulos por conta própria (negociações - dealing) e em nome de terceiros (corretagem - brokerage) para criar e manter os mercados secundários de produtos securitizados; e em prestar serviços de assessoria a emitentes, incluindo fusões e aquisições. Há empresas do lado da venda que definitivamente não podem ser consideradas bancos de investimento, pois se concentram na corretagem (ex. Charles Schwab) ou na negociação de títulos securitizados (ex. Tradebot) sem presença ativa nos mercados primários (isto é, sem participar da produção de novos títulos securitizados). $\bigcirc$ 
lado da compra, muitas vezes referido como setor de gerenciamento de ativos, é composto por empresas que gerenciam fundos de investimento (pensões, mútuos, hedge funds, capital de risco e outros) e por consultores de investimentos, que assessoram gestores de fundos e outras pessoas e organizações. No entanto, ao contrário dos gestores de fundos, essas empresas e consultores não tomam decisões reais de investimento. Em termos gerais, os bancos de investimento cruzam o limite entre o lado da venda e o lado da compra, já que há bancos de investimento que prestam serviços de gerenciamento de fundos e de consultoria em investimento. Em 2009, tanto o Goldman Sachs quanto o Morgan Stanley estavam entre os 50 maiores gestores de fundos do mundo de acordo com o valor dos ativos sob sua administração (Towers Watson, 2011). Os bancos de investimento também atuam como facilitadores de câmbio, uma vez que, sob certas condições, podem internalizar pedidos de compra e venda de seus clientes, combinando-os internamente, em vez de enviá-los para uma bolsa de valores (Wójcik, 201lb).

Vale ressaltar que, embora os bancos de investimento operem em todas as partes da indústria da securitização, as empresas do lado da compra ou os facilitadores de câmbio raramente passam para o lado da venda e não se envolvem diretamente com a indústria da securitização nos mercados primários. Esse envolvimento exclusivo na produção de títulos securitizados dá aos bancos de investimento acesso privilegiado à informação. Indo direto ao ponto: os bancos de investimento conseguem acessar qualquer parte da indústria da securitização, enquanto outras empresas dessa mesma indústria não têm acesso à riqueza de informação que os bancos de investimento desfrutam. Essa situação faz dos bancos de investimento o núcleo e elite da indústria da securitização, cujo poder de ganhos e geografia refletem seu status especial. Em 2008, a folha de pagamento média por pessoa nos bancos de investimento (definida de forma restrita devido à indisponibilidade de dados para uma definição ampla) foi de US \$341.000,00 anuais, quase o dobro da média dessa indústria e muito próximo do salário do presidente dos EUA. Os bancos de investimentos obtiveram a maior remuneração por pessoa em 2008 e o maior crescimento em salário por pessoa desde 1998 entre todas as categorias Naics. Colocando em perspectiva: 150 mil funcionários dos bancos de investimento ganham uma média de US\$341.000,00; em 2008, as 762 mil unidades tributárias (1\% das famílias dos EUA) de acordo com sua receita (excluindo ganhos de capital) ganharam em média US\$ 401.000,00 (Piketty; Saez, 2012). Esses números nos dão uma ideia da contribuição desse pequeno grupo profissional para a desigualdade de renda nos EUA. Os bancos de investimentos também apresentam a maior concentração geográfica da indústria da securitização. Em 2008, mais de $50 \%$ de todos seus funcionários trabalhavam em Manhattan, em contraste a menos de $20 \%$ de empregados em administração de fundos e aproximadamente 10\% em consultoria de investimentos, o que não é de se surpreender, visto que Goldman Sachs, Morgan Stanley, JPMorgan e Merrill Lynch (uma parte do Bank of America), os maiores bancos de investimento dos EUA para serviço completo, têm sede em Manhattan.

O poder dos bancos de investimento vai além do seu poder de compra. Pelo menos até 2008, os principais bancos de investimento estavam no topo da lista dos empregadores mais procurados entre profissionais graduados. Devido ao ambiente de trabalho de alta pressão e ao alto volume de negócios das equipes dos bancos de investimento (McDowell, 1997), esse mercado alimenta boa parte do resto do setor financeiro e dos principais grupos de executivos 
corporativos. Além disso, muitos fundos de investimento multimercado (hedge funds) formalmente independentes e outros fundos de investimento provavelmente são desmembramentos de bancos de investimento. $\bigcirc$ poder político desses bancos está relacionado à questão da "porta giratória" existente entre Wall Street, governo estadunidense e agências reguladoras, exemplificada por Henry Paulson e Robert Rubin, executivos da Goldman Sachs antes de serem nomeados secretários do Tesouro dos EUA. Como Rajan (2010) argumentou, mesmo que os banqueiros de investimento assumam posições governamentais e tenham as melhores intenções, eles provavelmente continuarão pensando como banqueiros, o que nos leva ao problema de "captura cognitiva". Os bancos de investimento também são um dos principais doadores dos políticos estadunidenses, o que aumenta o potencial de captura regulatória ("Principais levantadores de fundo de Obama são de Wall Street", 2007). Estima-se que entre 1998 e 2008, a indústria da securitização tenha gasto US\$ 500 milhões em contribuições de campanha e US\$ 600 milhões em lobby (Johnson; Kwak, 2010).

Além dos mercados de trabalho e da política, os bancos de investimento exercem seu poder por meio de ideias. Algumas das formas mais influentes de medir o valor econômico e o risco, e de interpretar o mapa da economia mundial, vieram de bancos de investimento. $\bigcirc$ conceito de Valor em Risco (VaR), que mede o risco de perda em uma carteira específica de ativos, foi desenvolvido pelo JPMorgan e tem sido amplamente utilizado no setor financeiro, tendo sido estipulado como método de avaliação de risco de mercado em 2004 em um acordo regulatório internacional conhecido como Basileia II (Ferguson, 2009). O acrônimo BRIC foi cunhado por Jim O' Neill do Goldman Sachs. O termo "mercados emergentes" tem origem na pesquisa do Banco Mundial, mas provavelmente a ferramenta mais influente para identificar e classificar os mercados emergentes é um conjunto de índices MSCI, desenvolvido por Morgan Stanley. Os bancos de investimento também foram promotores centrais da ideologia do "valor voltado para os acionistas", marginalizando os interesses de outras partes interessadas nas empresas e centralizando os preços das ações como medida suprema de valor corporativo (Ho, 2009).

A desconstrução da indústria da securitização apresentada nesta seção exemplifica o valor de uma abordagem de mesonível focada em securitização e não como um fenômeno abstrato associado a um mercado também abstrato, mas sim "um produto" que é fornecido por uma determinada indústria, inserida em certos locais (Wójcik 201la; Leyshon; Thrift, 2007). Como sugestão de avanços na área, futuras pesquisas podem analisar as relações de poder nas cadeias de valor de projetos específicos dos bancos de investimento, como a securitização de hipotecas. Esta seção também destacou a necessidade de uma abordagem integracionista na área de geografias de finanças (Pike; Pollard, 2010). Como mostrei, compreender o papel dos bancos de investimento exige uma análise econômica, política e cultural.

\section{Ascensão ao poder e transformação}

A ascensão dos bancos de investimento ao poder, que está no centro do fenomenal crescimento da indústria da securitização nas últimas três décadas, tem sido impulsionada principalmente por quatro grupos de fatores. $O$ primeiro tem a ver com a crescente demanda por serviços de investimento motivada pelo crescimento dos fundos de pensão, substituindo 
os sistemas de pensão autofinanciados (Clark, 2000). A legislação histórica nesse campo nos EUA foi a introdução de planos 401(k) em 1980, incentivando as pessoas a colocarem suas reservas nesses fundos. Estima-se que em setembro de 2011, as contas 401(k) totalizavam ativos de aproximadamente US\$ 3 trilhões, a maioria investida em fundos mútuos (Bloomberg, 2011). Os bancos de investimento poderiam usar esse aumento da quantia de fundos para vender serviços de gerenciamento e assessoria, mas mais importante do que isso é o fato de que as pensões financiadas geram demanda por novos títulos securitizados, cuja produção é o foco tradicional dos bancos de investimento.

O segundo grupo de fatores envolve a introdução de computadores e novas tecnologias de informação e comunicação (TIC), bem como teorias formais de investimento matemático, lideradas pela teoria moderna de portfólio. Devido ao valor da informação na indústria da securitização, essa indústria sempre teve domínio profundo sobre as TIC. A introdução de computadores pessoais e redes de computadores nos últimos 30 anos teve efeitos transformadores, o que gerou custos adicionais significativos, grande parte dos quais é relativamente fixa (criação de uma rede interna, conexões externas e um departamento de TI), intensificando as economias de escala (gasta-se menos e produz-se mais) presentes nos bancos de investimento, pressionando a captação de capital e incentivando que parcerias ou sociedades se convertam ao formato jurídico corporativo. A tecnologia também transformou as habilidades e o mercado de trabalho. Os banqueiros de investimento tradicionalmente adquiriam know-how no trabalho, desenvolviam habilidades relativamente específicas àquele local de trabalho e promoviam relacionamentos duradouros entre empregados e empregadores (Leyshon; Thrift, 1997). O poder crescente da computação facilitou o uso de modelos matemáticos nas finanças, incentivando o uso de habilidades genéricas e iniciais e alimentando a demanda por graduados em ciência, engenharia e tecnologia, com educação formal em finanças (como um MBA). As mudanças na natureza das competências, combinadas com uma forte demanda por mão de obra na indústria da securitização, aceleraram a rotatividade de pessoal e estimularam o desenvolvimento de altos planos de incentivo, com foco na remuneração por desempenho.

$\bigcirc$ terceiro fator crítico foi a desregulamentação, que permitiu aos bancos de investimento usar as novas tecnologias e atender à crescente demanda por serviços de investimento em um ambiente sustentando pela crença na autoregulação de mercados de livre competição. Embora a desregulamentação financeira nos EUA remonte à década de 1970, os principais atos que afetaram os bancos de investimento foram a revogação gradual da Lei Glass-Steagall entre 1996 e 1999 e a aprovação da Commodity Futures Modernization Act, de 2000 (Sherman, 2009). A primeira aboliu a separação obrigatória do investimento nos bancos comerciais (entre a indústria da securitização e o setor de crédito), em vigor desde 1933. Para os bancos de investimento já estabelecidos, essa revogação geraria mais concorrência, mas para seus funcionários e para a indústria da securitização de um modo geral, a separação significou oportunidades e expansão, como os bancos comerciais, liderados pelo Citigroup, que abriram grandes subsidiárias de bancos de investimento (Johnson; Kwak, 2010). A segunda lei, por sua vez, impediu a Commodity Futures Trading Commission de regular a maioria dos contratos de derivativos negociados fora das bolsas reguladas, incentivando a inovação e o crescimento da negociação de derivativos, um negócio crescente para os bancos de investimento. A nova concorrência e o 
paradigma predominante da autoregulação contribuíram para uma integração vertical legitimada nos bancos de investimento, incluindo a expansão da indústria da securitização do lado da venda para o lado da compra. Essa mistura crescente - serviços tanto para vendedores quanto para compradores de produtos securitizados e a negociação em nome de clientes que usam seus próprios recursos financeiros (proprietary trading) - intensificou os conflitos de interesses, mas acredita-se que esses conflitos de interesse foram neutralizados por controles internos e Chinese Walls dentro dos bancos de investimento e de bancos estruturados em holdings.

$\bigcirc$ quarto grupo de fatores envolve o crescimento internacional dos bancos de investimento e da indústria da securitização, visto que os bancos de investimento dos EUA criaram operações no exterior e a securitização e desregulamentação se expandiram para além dos EUA. Um momento-chave foi o Big Bang de 1986 no Reino Unido, que abriu esse mercado de ações para bancos estrangeiros. Do Reino Unido, a liberalização do mercado de produtos securitizados se difundiu para o resto da Europa, com a securitização tornando-se um dos leitmotifs da integração financeira europeia impulsionada pela Diretiva de Serviços de Investimento (DSI) de 1996 e consolidada pela Diretiva de Mercados e Instrumentos Financeiros (DMIF), em vigor desde 2007. A DSI criou um passaporte europeu único para as empresas de investimento, facilitando as operações pan-europeias das empresas europeias e não europeias. Uma investigação da propriedade corporativa transfronteiriça em 2000 mostrou o domínio dos investidores estadunidenses e dos bancos de investimento dos EUA como principais intermediários no processo de integração do mercado de capitais europeu, levando à conclusão de que o processo pode ser entendido como a "americanização" do mercado de capitais europeu (Wójcik, 2002). A DMIF abriu caminho para que novas localidades de negociação pudessem competir com as bolsas de valores tradicionais e, em 2012, tudo indica que os maiores proprietários tanto de tradicionais quanto de novas empresas de negociação de títulos, bem como seus principais clientes, são os bancos de investimento e investidores institucionais dos EUA (Wójcik, $201 \mathrm{lb}$ ). Além da Europa, a liberalização financeira nos mercados emergentes e em desenvolvimento, promovida pelo FMI, bem como as negociações da Rodada Doha da Organização Mundial de Comércio que promovem o livre comércio nos serviços de negócios, abriram novas oportunidades para os bancos de investimento (Stiglitz, 2002; Johnson; Kwak, 2010).

Em suma, nas três últimas décadas, os bancos de investimento, como núcleo e elite da indústria da securitização, cresceram em tamanho e poder e se transformou. No fim da década de 1970, normalmente se organizavam como pequenas sociedades especializadas em concessão de crédito e serviços de consultoria, que ofereciam empregos lucrativos, em sua maioria para toda a vida, além de relacionamentos de longo prazo com clientes, construção de confiança e relativamente pouca ciência ou hardware envolvidos nesse processo. Trinta anos depois, os bancos de investimento estão completamente diferentes, dominados por corporações multinacionais com estruturas de propriedade diluídas, algumas empregando dezenas de milhares de pessoas e se diversificando em todas as áreas da indústria da securitização. Essas empresas se concentram na negociação de papeis, com base em tecnologia e engenharia financeira. Há mais de 30 anos, seus funcionários e executivos são mais bem remunerados do que qualquer outro grupo profissional semelhante nos EUA. 
Se julgarmos um setor econômico por sua dinâmica, salários ou lucratividade, os bancos de investimento são um bom candidato para a distinção de indústria mais bem sucedida dos últimos 30 anos. No entanto, há duas preocupações fundamentais nesse cenário. Primeiramente, a mudança de foco de construção de relacionamento e confiança para a engenharia financeira e a negociação sugere uma alteração com objetivos e incentivos de curto prazo. As atividades tradicionais dos bancos de investimento que se concentram nas finanças corporativas certamente continuam se orientando pelo relacionamento com os clientes; no entanto, as receitas dessas atividades foram bastante reduzidas pelas de trading (Morrison; Wilhelm, 2007). O segundo problema é que o boom da indústria foi impulsionado por seu poder político e ideológico. Em um estudo sobre a remuneração do setor financeiro dos EUA entre 1909 e 2006, Philippon e Reshef (2009) demonstraram que os pacotes de alta remuneração da última década estão relacionados à desregulamentação, não podendo ser justificados com base em qualificação exigida, complexidade e segurança dos empregos ou uso de novas tecnologias. Esses autores estimaram que, em 2006, os profissionais da área financeira foram pagos cerca de 40\% excessivamente. Curiosamente, no entanto, Philippon e Reshef (2009) não prestaram muita atenção ao fato de que aumentos nas remunerações na indústria da securitização levaram à redução dos salários no resto do setor financeiro. Assim, uma grande questão permanece: até que ponto os bancos de investimento e a indústria da securitização prosperaram às custas do resto da economia e da sociedade?

\section{O capitalismo dos bancos de investimento fora dos EUA}

Este artigo se concentra nos EUA, mas o capitalismo dos bancos de investimento é um fenômeno que se aplica a outros países. Embora os dados sistemáticos sobre a remuneração em diferentes partes do setor financeiro não estejam disponíveis para outros países, as características básicas do emprego na indústria da securitização em comparação àqueles no setor de crédito e seguros nas cinco maiores economias fora dos EUA (China, França, Alemanha, Japão e Reino Unido) são apresentados nas Figuras 11 e 12, incluindo a Suíça, uma localização importante de serviços financeiros. Como os dados históricos para a China estão disponíveis apenas para Hong Kong, a Figura 11 refere-se somente a Hong Kong, ao passo que a Figura 12 mostra dados para toda a China, incluindo Hong Kong.

$\bigcirc$ que se destaca nesses dados é que o aumento espetacular dos níveis de emprego na indústria da securitização documentado dos EUA para o período 1998-2008 não foi uma exceção. A França, a Alemanha, a Suíça e o Reino Unido registraram aumentos muito maiores em tamanho absoluto do que os EUA, com variação de 42\% na Alemanha a 98\% na Suíça, e em todos esses países, o crescimento da indústria da securitização ofuscou o de crédito e seguros (Figura 11). Na verdade, na Alemanha e no Reino Unido, os níveis de emprego nos setores de crédito e de seguros caíram. Em Hong Kong, o crescimento desses setores aproximou-se muito do da indústria da securitização, provavelmente porque o mercado chinês ainda está longe da saturação, em termos de produtos bancários e de seguros básicos. A única exceção é o Japão, onde o emprego na indústria da securitização caiu mais de 30\%, número maior do que os setores de crédito e de seguros. Essa redução pode ser explicada pelo domínio da dívida pública e a relativa estagnação das finanças privadas japonesas, incluindo os mercados imobiliários e de ações (Koo, 2008). 
Figura 11 - Mudança em níveis de emprego de 1998 a 2008

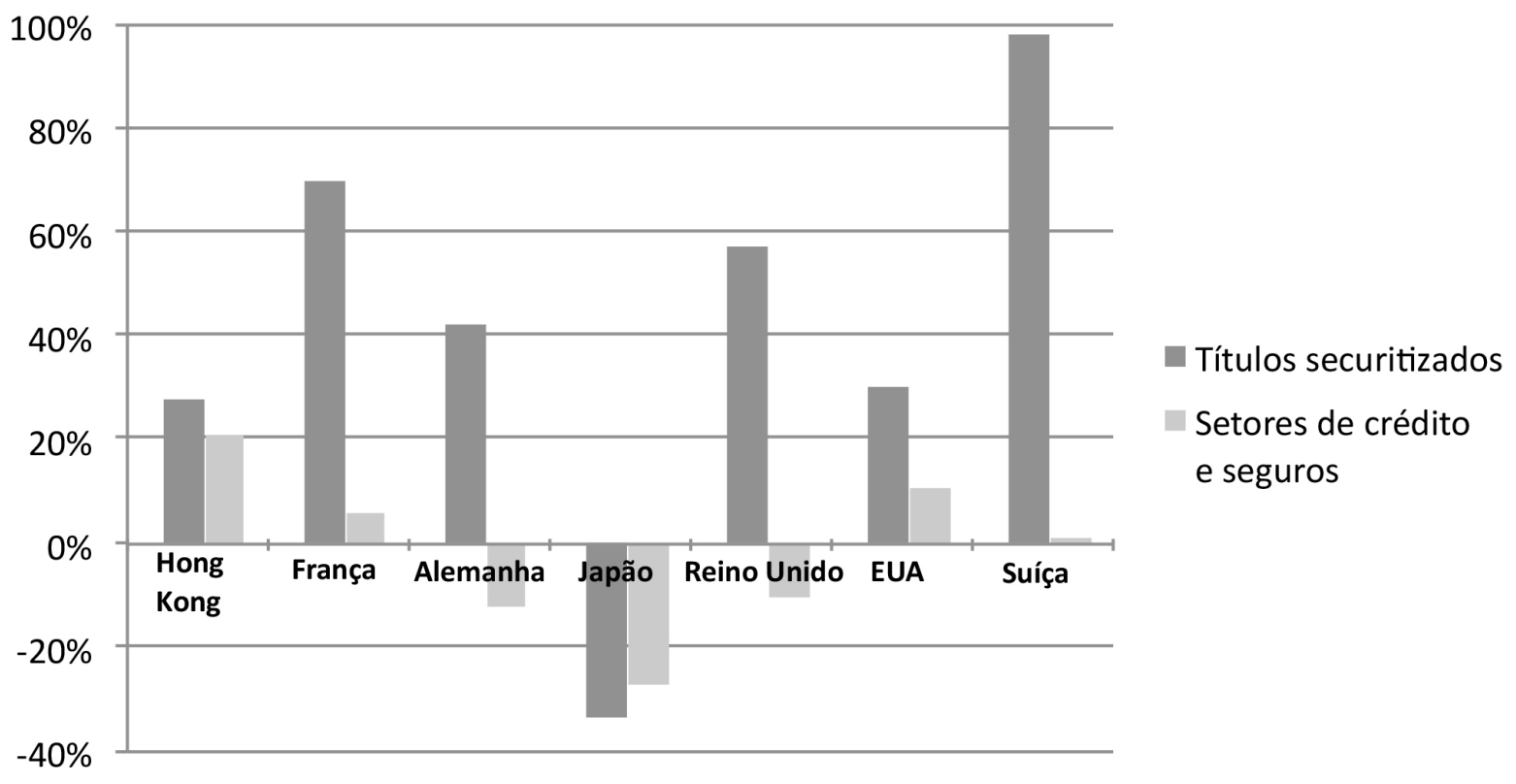

fonte: $O$ autor, com base em dados do Serviço Nacional de Estatística (China); Unistatis (França); Bundesagentur für Arbeit Statistik (Alemanha); Serviço Japonês de Estatística Nomis e Escritório Nacional de Estatísticas (Reino Unido); Padrões Comerciais Municipais, Gabinete de Censo (EUA) e Instituto Federal de Estatística (Suíça).

\section{Figura 12 - Concentração de empregos nas principais cidades em 2008}

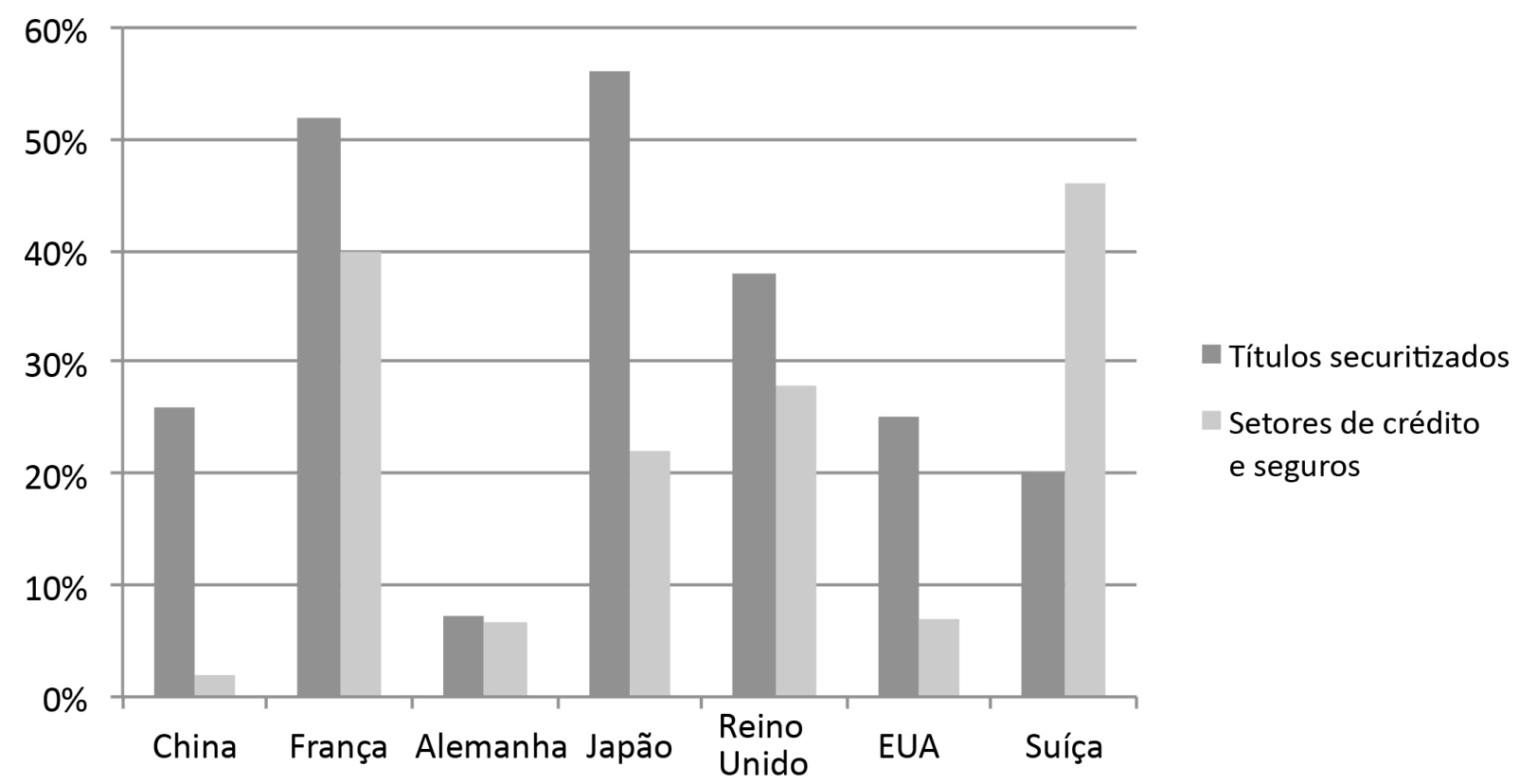

fonte: $O$ autor, com base nos mesmos dados da Figura 11. As principais cidades são definidas como Hong Kong (China), Paris (França), Frankfurt (Alemanha), Tóquio (Japão), Londres (Reino Unido), Área Metropolitana de Coleta de Estatísticas de Nova York, Nova Jersey e Long Island (EUA) e Zurique (Suíça).

A Figura 12 mostra a concentração do emprego nas principais cidades de vários países em 2008, indicando uma maior concentração geográfica da indústria da securitização do que nos de crédito e seguros nos EUA e também na China, na França, Alemanha, Japão e Reino Unido. Tóquio, por exemplo, teve $22 \%$ dos empregos em crédito e seguros, mas 56\% na indús- 
tria da securitização em 2008. Em termos relativos, a maior discrepância entre a participação da principal cidade na indústria da securitização em relação aos setores de crédito e de seguro foi observada na China, em que Hong Kong, responsável por $2 \%$ do emprego em crédito e seguros, comandava uma participação de $26 \%$ na indústria da securitização. A Suíça, no entanto, não seguiu esse padrão, e a Alemanha o fez muito fracamente. Zurique representou 46\% do emprego em crédito e seguros na Suíça, com apenas 20\% da mão de obra na indústria da securitização. Na Alemanha, a participação de Frankfurt na indústria da securitização foi de apenas 7\%, um pouco mais do que a participação nos setores de crédito e de seguros. A indústria da securitização na Alemanha e na Suíça está muito mais dispersa espacialmente, com grandes centros de gerenciamento de ativos como Munique e Genebra em posição muito próxima de Frankfurt e Zurique, respectivamente. Essa dispersão da indústria da securitização reflete uma natureza espacial relativamente descentralizada e multipolar do setor financeiro na Alemanha e na Suíça (Klagge; Martin, 2005).

Além dos padrões básicos de emprego, realmente há diferenças na estrutura e no papel da indústria da securitização. Os países da Europa Continental, por exemplo, nunca tiveram uma separação formal entre bancos de investimento e comerciais, o que seria equivalente à Lei Glass-Steagall nos EUA. O modelo de banco universal foi adotado pela União Europeia e mais recentemente pelo Japão, e está sendo considerado pela China. Barclays, Deutsche Bank e UBS, por exemplo, têm algumas das maiores operações como bancos de investimento do mundo, porque esses bancos universais são mais parecidos com o Citigroup do que com o Goldman Sachs ou o Morgan Stanley. De fato, pode-se entender a entrada de bancos universais não estadunidenses nas operações como bancos de investimento, indicada na Figura 11, como uma das motivações para a revogação da Lei Glass-Steagall nos EUA, um movimento que facilitou a liderança internacional contínua dos bancos de investimento estadunidenses.

Em resumo, uma breve visão geral internacional complica a análise, mas, ao mesmo tempo, destaca a importância do estudo sobre bancos de investimento e sobre a indústria da securitização pelo viés da geografia econômica. Os padrões básicos não se reduzem a uma simples distinção entre economias de mercado liberais e coordenadas, como defendido pelas diferentes linhas do pensamento capitalista (Hall, P.; Soskice, 2001). A ascensão da indústria da securitização mostrou-se comum fora dos EUA; no entanto, há importantes exceções nessa tendência, bem como diversidades em seu registro espacial. Em última análise, é provável que o capitalismo dos bancos de investimentos se diversifique, estruturando-se em diferentes formas e variando em níveis de intensidade em diferentes escalas de análise, incluindo o nível subnacional das cidades e regiões (Peck; Theodore 2007; Dixon, 2010).

\section{A crise financeira global e o futuro}

O boom dos empréstimos hipotecários (incluindo o segmento de subprime) e a bolha dos preços imobiliários entre o final da década de 1990 e 2000 foram sustentados por taxas de juros relativamente baixas mantidas pelo Banco Central dos EUA, com apoio do governo estadunidense para a expansão da casa própria organizada pelas empresas Fannie Mae, Freddie Mac e Ginni Mae e financiadas pelo governo (Ron Martin, 2011). Entretanto, foram os bancos de investimento (incluindo as subsidiárias de investimento das holdings bancárias) que centraliza- 
ram a produção e distribuição de produtos securitizados com base em hipotecas, incluindo os de subprime, e inventaram obrigações de dívida coleteralizadas (CDO), com mutações sob a forma de CDO ao quadrado e ao cubo, bem como swaps de inadimplência de crédito (CDS). Esses bancos compunham as principais instituições privadas que compravam as hipotecas e outros títulos securitizados por ativos de empréstimos e empresas financiadas pelo governo, para convertê-los em CDO, usando suas redes globais para vender esses instrumentos para investidores em todo o mundo. Nesse processo, eles pagavam agências de classificação para avaliar os CDO de modo que pudessem receber investimentos de fundos de pensão e outros investidores institucionais. Tett (2009) também informou que muitas vezes eram os próprios bancos de investimento que organizavam cursos sobre CDO para as agências de classificação.

Além de serem grandes inovadores e veículos de produção e distribuição de CDO, os bancos de investimento acumularam em suas carteiras grandes volumes de títulos securitizados por ativos, $\mathrm{CDO}$ e ativos relacionados. Em parte, isso era inevitável, porque eles precisavam comprar pools de hipotecas antes de processá-las e vendê-las. Ademais, os bancos de investimento mantiveram alguns CDO em suas próprias carteiras de investimento, além de comprar CDO e CDS de outras instituições, atraídos por taxas de retorno relativamente altas. Essas compras foram realizadas com dinheiro emprestado, e não com o próprio capital dos bancos. Os veículos utilizados pelos bancos de investimento para o processamento de títulos securitizados por ativos e investimentos em CDO e CDS, referidos principalmente como veículos de investimentos estruturados e especiais (SIV e SPV), foram mantidos fora do balancete como entidades legais separadas. Para disfarçá-los ainda mais, os SIV e os SPV foram regularmente registrados em jurisdições secretas e paraísos fiscais, embora o escopo dessa estratégia ainda seja desconhecido (Comitê de Basileia para Supervisão Bancária 2009). Em suma, os bancos de investimento estavam no cerne do que veio a ser conhecido como shadow banking system (Pozsar et al., 2010). A participação dos corretores (bancos de investimento fora das holdings bancárias) nos ativos financeiros totais do setor privado aumentou de menos de 2\% em 1980 para 22\% em 2007 (Pozsar et al., 2010).

No posfácio da obra The Ascent of Money, Ferguson (2009) sugeriu que a CFG resultou na extinção dos bancos de investimento estadunidenses, com a falência do Lehman Brothers, após Bear Stearns e Merrill Lynch terem sido assumidos por bancos comerciais (JPMorgan e Bank of America, respectivamente), e Goldman Sachs e Morgan Stanley terem se convertido em holdings bancárias. No entanto, é mais provável que estejamos testemunhando uma adaptação e mutação desses bancos, e não sua extinção. Embora os bancos comerciais tenham assumido o controle de alguns bancos de investimento, isso não resulta necessariamente em uma redução da cultura de banco de investimento no setor financeiro. As três últimas décadas viram muitos bancos comerciais, incluindo o Citigroup, o Deutsche Bank, o Royal Bank of Scotland e o Credit Suisse, permeados ou mesmo dominados pela cultura dos bancos de investimento, com operadores e banqueiros de investimentos tornando-se seus executivos. Em segundo lugar, as falências de alguns bancos de investimento e empresas de securitização podem significar maiores fatias de mercado para os que permaneceram no mercado, independentemente de seu formato legal. Na verdade, em 2009, Goldman Sachs, Morgan Stanley, Credit Suisse e Deutsche Bank tiveram as maiores margens de lucro (proporção de lucro líquido por 
receita) desde o início de 2006 (Figura 13), e o Goldman Sachs registrou o maior valor absoluto de lucro líquido no período 2006-2009. Acredita-se que a de Nova York teria indústria da securitização teria perdido 30 mil, ou 16\%, de seus empregos durante a crise, mas no segundo semestre de 2010, foram criados 3.600 novos postos e o pool global de remuneração em 2010 foi maior do que em 2009 (dados do escritório do contador-chefe do estado de Nova York em 2011). Esse não parece ser o cenário de uma indústria que está se retirando do mercado. Talvez a única real ameaça para os bancos de investimento seja uma re-regulação financeira. No início de 2012 (data de produção deste artigo), com pacotes de reforma financeira ainda em debate nos dois lados do Atlântico, era muito cedo para julgar o impacto dessa iniciativa nos bancos de investimentos. Questões de especial relevância para esses bancos são a regulamentação das práticas de remuneração, as restrições à negociação de propriedade e a separação entre bancos de investimento e bancos comerciais.

\section{Figura 13 - Margem de lucro líquido dos principais bancos}

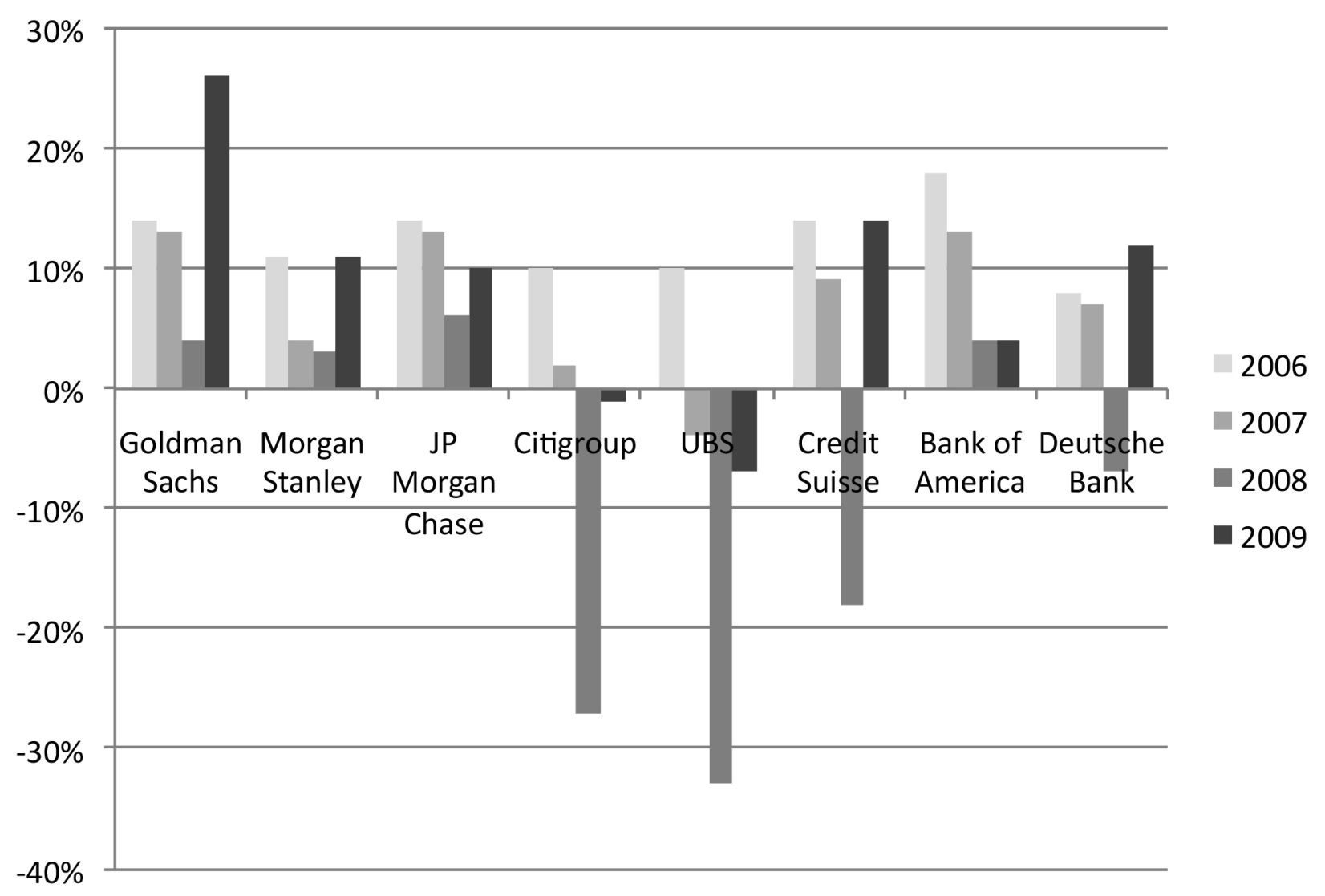

fonte: $\bigcirc$ autor, com base nos dados da Factiva Dow Jones.

Segundo alguns autores, incluindo Ferguson (2009), um grande desafio para os bancos de investimento virá dos sovereign wealth funds (SWF) ou Fundos Soberanos. Até certo ponto, os SWF podem ser vistos como apólices de seguros das economias emergentes contra os caprichos dos mercados financeiros globais voláteis, demonstrados mais agudamente na crise financeira asiática de 1997-1998 (Clark; Wójcik, 2001). Os SWF são reservas em moeda estrangeira, com as quais esses países podem se defender contra súbitas saídas de dinheiro sem depender do FMI (Clark et al., 2010). É irônico notar que, embora os bancos de investimento 
estivessem entre as instituições que mais fugiram dos mercados asiáticos em 1997-1998, 10 anos depois, alguns SWF vieram em seu resgate com injeções vitais de capital. Em 2008, o GIC Private Ltd. (Government of Singapore Investment Corporation), investiu no Citigroup e no UBS, o ADIA (Abu Dhabi Investment Authority) e o KIA (Kuwait Investment Authority) também investiram no Citigroup, já o KIC (Korea Investment Corporation) e o Temasek Holdings investiram no Merill Lynch, o ClC (China Investment Corporation) investiu no Morgan Stanley e o QIA (Qatar Investment Authority) no Credit Suisse. Os comentaristas financeiros viram nesse cenário uma oportunidade única para os SWF engolirem os principais bancos de investimento, mas logo essa visão se mostrou equivocada, já que em 2009, os SWF perderam muito dinheiro com esses investimentos e os venderam rapidamente. No final de 2010, as únicas participações dos SWF nos bancos de investimento dos EUA ou da Europa (bancos com grandes operações bancárias de investimento) foram os fundos do CIC no Morgan Stanley (12,6\% do capital social) e do QIA no Credit Suisse (5,3\%).

Relembremos a estrutura da indústria da securitização por um momento. Os SWF são fundos de investimento controlados pelo governo e, desse modo, operam no lado da compra na indústria da securitização global. Embora tenham chegado a quase US\$ 4 trilhões em 2010, seus ativos ainda representam somente $5 \%$ dos ativos convencionais em gestão no mundo, compreendendo apenas um sétimo dos ativos dos fundos de pensão (TheCityUK, 2010). Os bancos de investimento floresceram durante a expansão dos fundos de pensão nos EUA e na Europa nos últimos 30 anos e, assim, o tamanho dos próprios SWF reflete tanto uma oportunidade como um desafio para os bancos de investimento. Os SWF, no entanto, tendem a buscar investimentos ativos e estratégicos, em vez de passivos (típicos de fundos de pensões e fundos mútuos), incluindo a aquisição de participações de controle nos setores militar, aeroespacial e automobilístico nos quais seus países de origem carecem de know-how (Haberly, 2011). Essa pode ser uma estratégia que intencionalmente se desvia das cadeias de longo prazo de intermediação e securitização e se aproxima das estratégias de investimento passivo, cujos principais líderes e inovadores são os bancos de investimento. No mundo pós-CFG, os banqueiros de investimento estão interessados em realizar negócios com os SWF. É provável que façam lobby para que os SWF tornem-se semelhantes aos fundos de pensão - recipientes passivos de fundos -, dependendo da expertise dos bancos de investimento e do resto da indústria da securitização. Não é de se surpreender que o Fundo de Pensão do Governo da Noruega, que segue uma estratégia de investimento passivo (com grande parte dos fundos administrados pela City Londrina e por Wall Street), seja considerado nos EUA e na Europa como modelo de transparência e governança (Clark; Monk, 2010). Os SWF são os principais novos players da indústria da securitização global e sua relação com os bancos de investimento é um dos pilares da paisagem financeira mundial emergente.

\section{Conclusões e implicações}

Este artigo concentrou-se no papel dos bancos de investimento na economia dos EUA nos últimos 30 anos, incluindo a recente crise financeira global (CFG). Esse é um tema controverso, com a mídia imputando a culpa aos bancos de investimento, com histórias sobre bônus exorbitantes e casos de práticas empresariais duvidosas, ao mesmo tempo em que estudos 
acadêmicos influentes atribuem à crise o fracasso do governo e os desequilibrios mundiais. Para apresentar uma perspectiva da geografia econômica sobre esse debate, associei a análise de padrões básicos de emprego no setor financeiro à análise da posição dos bancos de investimento nesse setor, discutindo também a ascensão desses bancos ao poder nos últimos 30 anos e seu envolvimento na CFG. Assim, mostrei seu papel central na indústria da securitização, que até o momento é o segmento mais expansivo do setor financeiro estadunidense. Realmente, enquanto o emprego geral no setor financeiro manteve-se estável, tanto o emprego como a remuneração na indústria da securitização cresceram. $\bigcirc$ desenvolvimento do setor financeiro dos EUA nos últimos 30 anos pode ser resumido numa palavra: securitização. $\bigcirc$ processo de securitização foi organizado em Manhattan (por meio de Wall Street), lugar que pode ser entendido como um centro de securitização, e não como um centro financeiro. A análise também indicou que a indústria da securitização tem contribuído sobretudo para a crescente desigualdade de renda entre os setores financeiro e não financeiro, entre Manhattan e o resto dos EUA e dentro de Manhattan.

Os bancos de investimento, que funcionam de forma independente e como parte dos bancos comerciais, são o núcleo e a elite da indústria da securitização, permeando todos os aspectos desse mercado e representando o grupo profissional mais bem recompensado da indústria da securitização. Além do poder de compra, sua influência se estende à política e às ideias que orientam as práticas comerciais no setor corporativo. $\bigcirc$ aumento do poder dos bancos de investimento nos últimos 30 anos é uma consequência da crescente demanda por serviços de investimento, mudanças tecnológicas, desregulamentação e globalização. Junto à indústria da securitização de modo geral, os bancos de investimento aproveitaram e se adaptaram a essas mudanças, tornando-se um dos setores mais bem-sucedidos da economia estadunidense. No entanto, a CFG revelou o lado sombrio desse sucesso. Os banqueiros de investimento inventaram muitos dos instrumentos financeiros usados para aumentar o volume de negócios na cadeia de securitização posicionados no centro do shadow banking system, muitas vezes usando métodos para dissimular seu funcionamento. A reputação desses banqueiros ajudou a legitimar a cadeia e o sistema aos olhos dos investidores.

As descobertas deste artigo contrariam as versões comuns das causas da CFG, que começa com a suposição de que o setor financeiro se tornou desintermediado nas últimas décadas, com os bancos se tornando menos, e os mercados mais importantes. Em 2008, os EUA tinham mais pessoas do que nunca trabalhando em intermediação financeira, com níveis de emprego em intermediação tão altos quanto em 1978, com participação quase duas vezes maior em folha de pagamento total. Essa situação deve-se principalmente à indústria da securitização que, no núcleo do setor financeiro, cresceu em tamanho geral, tamanho de empresas líderes, remuneração e poder.

A geografia econômica pode contribuir para desmistificar o setor financeiro e para explicar a CFG por meio do estudo da indústria da securitização e de seu núcleo: os bancos de investimentos. Este artigo apresentou um estudo exploratório, cuja continuidade pode ser desenvolvida por várias linhas de investigação. Com base em dados sobre o lucro obtido pelos bancos de investimento e pela indústria da securitização, além de informações sobre emprego e remuneração, pode-se averiguar tanto o nível de desintermediação quanto o de concorrência 
nesse setor. Uma análise internacional das mudanças em nível de emprego pode ser usada para investigar a mobilidade dos bancos e dos banqueiros de investimento, muitas vezes usada por insiders da indústria para melhorar seu poder de barganha com o governo. Uma análise adicional sobre a posição dos bancos de investimento nas cadeias de valor e nas estruturas de poder do setor financeiro pode nos ajudar a questionar as reivindicações de poder dos investidores institucionais e do capitalismo fiduciário. Investigações sobre os bancos de investimento também podem oferecer uma perspectiva única sobre a trajetória dos mercados de commodities e de carbono (Knox-Hayes, 2009), nos quais esses bancos são os principais players. Sem contar o papel dos bancos de investimento e da indústria da securitização (incluindo os SWF) na formação do mapa dos centros financeiros globais, incluindo a discutida mudança para a Ásia.

Ademais, os estudos sobre bancos de investimento são certamente fundamentais para uma abordagem econômica-cultural na geografia. As pessoas que iniciaram suas carreiras na indústria da securitização na década de 1980 e no início da década de 1990 compuseram a elite de uma onda de yuppies empregados em serviços produtivos em ascensão. No fim da década de 1990, os boêmios burgueses (bobos ou bourgeois bohemians), elite das indústrias criativas, roubaram a cena e chamaram atenção das ciências sociais. A elite de yuppies foi relegada às sombras. Mas, enquanto os bobos perfaziam a fachada do capitalismo no fim da década de 1990 e nos anos 2000, a elite de yuppies chegava ao auge de sua carreira na indústria da securitização, alegremente dando as cartas nos bastidores, construindo um sistema bancário paralelo (shadow banking system) e ganhando fortunas com isso. No limite da análise, pode-se argumentar que a indústria e as classes criativas foram o espetáculo secundário (sideshow) da financeirização e da securitização. Há anos, Wrigley, Currah e Wood (2003) apontaram a necessidade de mais pesquisas sobre os bancos de investimento como uma das chaves para se compreender a dinâmica do capitalismo. Essa convocação é agora mais urgente do que nunca.

\section{Referências}

ALLEN, J. Three space of power: Territory, networks, plus a topological twist in the tale of domination and authority. Journal of Power, v. 2, p. 197-212, 2009.

AMIN, A.; THRIFT, N. The Blackwell cultural economy reader. Oxford: Blackwell, 2004.

ARRIGHI, G. The long twentieth century: Money, power, and the origins of our times. London: Verso, 2010.

BASEL Committee on Banking Supervision. Report on special purpose entities. Basel: Bank for International Settlements, 2009.

BEAVERSTOCK, J. V. World city networks from below: International mobility and inter-city relations in the global investment banking industry. In: TAYLOR, P. J. et al. (Ed.). Cities in globalization: Practices, policies, theories. London: Routledge, 2007. p. 52-71.

BHAGWATI, J. The capital myth: The difference between trade in widgets and dollars. Foreign Affairs, v. 77, p. 7-12, 1998. 
BLOOMBERG Businessweek. Big banks go after 40lk trillions, 2011. Disponível em: http:// www.businessweek.com/magazine/content/11_15/b4223053701239.htm. Acesso em: 12 set. 2017.

BRAKMAN, S.; GARRETSEN, H.; MARREWIJK, C. The new introduction to geographical economics. Cambridge: Cambridge University Press, 2009.

CHRISTOPHERS, B. Complexity, finance, and progress in human geography. Progress in Human Geography, v. 33, p. 807-24, 2009.

CLARK, G. L. Pension fund capitalism. Oxford: Oxford University Press, 2000. et al. Symposium: Sovereign fund capitalism. Environment and Planning A, v. 42, p. 2271-2291, 2010.

CLARK, G. L.; MONK, A. The legitimacy and governance of Norway's sovereign wealth fund: The ethics of global investment. Environment and Planning A, v. 42, p. 1723-1738, 2010.

CLARK, G. L.; WÓJCIK, D. The geography of finance: Corporate governance in a global marketplace. Oxford: Oxford University Press, 2007.

. The city of London in the Asian crisis. Journal of Economic Geography, v. 1, p. 107-130, 2001.

DICKEN, P.; LLOYD, P. E. Location in space: Theoretical perspectives in economic geography. New York: Harper Collins, 1990.

DIXON, A. D. Variegated capitalism and the geography of finance: Towards a common agenda. Progress in Human Geography, v. 35, p. 193-210, 2010.

EPSTEIN, G. (Ed.). Financialization and the world economy. Cheltenham, UK: Edward Elgar, 2005.

et al. After the great complacence: Financial crisis and the politics of reform. Oxford: Oxford University Press, 2011.

FERGUSON, N. The ascent of money: A financial history of the world. London: Penguin, 2009.

FRENCH, S.; LEYSHON, A.; WAINWRIGHT, T. Financializing space, spacing financialization. Progress in Human Geography, v. 35, p. 798-819, 2011.

FROUD, J. et al. Financialization and strategy: Narrative and numbers. London: Routledge, 2006.

GOWAN, P. Crisis in the heartland: Consequences of the new Wall Street system. New Left Review, v. 55, p. 5-29, 2009.

HABERLY, D. Strategic sovereign wealth fund investment and the new alliance capitalism: A network mapping investigation. Environment and Planning A, v. 43, p. 1833-1852, 2011. 
HALL, S. Knowledge makes the money go round: Conflicts of interest and corporate finance in London's financial district. Geoforum, v. 38, p. 710-719, 2007.

; SOSKICE, D. Varieties of capitalism: The institutional foundations of comparative advantage. Oxford: Oxford University Press, 2001.

HARRIS, L. Trading and exchanges: Market microstructure for practitioners. Oxford: Oxford University Press, 2003.

HARVEY, D. Roepke lecture in economic geography: Crises, geographic disruptions and the uneven development of political responses. Economic Geography, v. 87, p. 1-22, 2011.

Social justice and the city. London: Edward Arnold, 1973.

HO, K. Liquidated: An ethnography of Wall Street. Durham, NC: Duke University Press, 2009 .

JOHNSON, S.; KWAK, J. 13 bankers: Wall Street takeover and the next financial meltdown. New York: Pantheon, 2010.

JONES, A. The "global city" misconceived: The myth of "global management" in transnational service firms. Geoforum, v. 33, p. 335-350, 2002.

KLAGGE, B.; MARTIN, R. Decentralized versus centralized financial systems: Is there a case for local capital markets? Journal of Economic Geography, v. 5, p. 387-422, 2005.

KNOX-HAYES, J. The developing carbon financial service industry: Expertise, adaptation and complementarity in London and New York. Journal of Economic Geography, v. 9, p. 749-778, 2009.

KOO, R. The Holy Grail of macroeconomics: Lessons from Japan's great recession. Singapore: John Wiley \& Sons, 2008.

KRIPPNER, G. R. The financialization of the American economy. Socio-Economic Review, v. 3, p. 173-208, 2005.

LANDIER, A.; NAIR, V. B.; WULF, J. Trade-offs in staying close: Corporate decision making and geographic dispersion. Review of Financial Studies, v. 22, p. 1119-1148, 2009.

LANGLEY, P. The everyday life of global finance. Oxford: Oxford University Press, 2008.

LEYSHON, A.; THRIFT, N. The capitalization of almost everything: The future of finance and capitalism. Theory, Culture and Society, v. 24, p. 97-115, 2007.

Money/space: Geographies of monetary transformation. London: Routledge, 1997.

MARTIN, Randy. Financialization of daily life. Philadelphia: Temple University Press, 2002.

MARTIN, Ron. The local geographies of the financial crisis: From the housing bubble to economic recession and beyond. Journal of Economic Geography, v. 11, p. 587-618, 2011. 
(Ed.). Money and the space economy. Chichester, UK: John Wiley \& Sons, 1999.

MASSEY, D. Spatial divisions of labour: Social structures and the geography of production. New York: Routledge, 1995.

McDOWELL, L. Capital culture: Gender at work in the city. Oxford, U.K.: Blackwell, 1997.

MISHKIN, F. S. The economics of money, banking, and financial markets. Boston: Pearson, 2006.

MORRISON, A.; WILHELM, W. Investment banking: Institutions, politics, and law. Oxford, U.K.: Oxford University Press, 2007.

OBAMA top fundraiser on Wall Street. Washington Post, 18 abr. 2007.

OFFICE of the New York State Comptroller. 2011. DiNapoli: Wall Street bonuses declined in 2010. Disponivel em: http://www.osc.state.ny.us/press/releases/febl1/02231la.htm. Acesso em: 12 set. 2017.

PECK, J.; THEODORE, N. Variegated capitalism. Progress in Human Geography, v. 31, p. 731-772, 2007.

PHILIPPON, T., RESHEF, A. Wages and human capital in the U.S. financial industry: 19092006. Discussion Paper 7282. London: Centre for Economic Policy Research, 2009.

PIKE, A.; POLLARD, J. Economic geographies of financialization. Economic Geography, v. 86, p. 29-51, 2010.

PIKETTY, T.; SAEZ, E. Income inequality in the United States, 1913-1998. Quarterly Journal of Economics, v. 118, p. 1-39, 2012.

POZSAR, Z. et al. Shadow banking. Staff report 458. New York: Federal Reserve Bank of New York, 2010.

RAJAN, R. Fault lines: How hidden fractures still threaten the world economy. Princeton: Princeton University Press, 2010.

SAVAGE, M.; WILLIAMS, K. Remembering elites. Chichester, UK: Wiley-Blackwell, 2008.

SHERMAN, M. A short history of financial deregulation in the United States. Washington D.C.: Centre for Economic and Policy Research, 2009. Disponível em: http://www.openthegovernment.org/otg/dereg-timeline-2009-07.pdf. Acesso em: 12 set. 2017.

SHILLER, R. The subprime solution: How today's global financial crisis happened, and what to do about it. Princeton: Princeton University Press, 2008.

SINGER, P. Marx: A very short introduction. Oxford: Oxford University Press, 2000.

SKIDELSKY, R. Keynes: A very short introduction. Oxford: Oxford University Press, 2010. 
STIGLITZ, J. Freefall: Free markets and the sinking of the global economy. London: Allen Lane, 2010.

Globalization and its discontents. London: Penguin, 2002.

TALEB, N. The black swan: The impact of the highly improbable. London: Penguin, 2008.

TETT, G. Fool's gold: How unrestrained greed corrupted a dream, shattered global markets and unleashed a catastrophe. London: Abacus, 2009.

THECITYUK. Fund Management, 2010. Disponível em: www.thecityuk.com/assets/Uploads/Fund-management-2010.pdf. Acesso em: 12 set. 2017.

TOWERS WATSON, 2011. The world's largest asset managers. Disponível em: www.towerswatson.com/united-kingdom/research/2942. Acesso em: 12 set. 2017.

WARF, B. Financial services and inequality in New York. Industrial Geographer, v. 2, p. 110-126, 2004.

WÓJCIK, D. Securitization and its footprint: The rise of the US securities industry centres 1998-2007. Journal of Economic Geography, v. 11, p. 925-947, 2011 a.

The global stock market: Issuers, investors, and intermediaries in an uneven world. Oxford, U.K.: Oxford University Press. $201 \mathrm{lb}$.

Cross-border corporate ownership and capital market integration in Europe: Evidence from portfolio and industrial holdings. Journal of Economic Geography, v. 2, p. 455-492, 2002.

WRIGLEY, N.; CURRAH, A.; WOOD, S. Investment bank analysts and knowledge in economic geography. Environment and Planning A, v. 35, p. 381-387, 2003. 